\title{
Application of thermal comfort assessment models to indoor areas near glazed walls - experimental evaluation
}

\author{
António M. Oliveira (Main and Corresponding Author) \\ Polytechnic Institute of Viseu, School of Technology and Management, \\ Campus Politécnico de Repeses, 3504-510, Viseu (Portugal) \\ amffo@estgv.ipv.pt \\ https://orcid.org/0000-0002-4157-8234
}

\section{Helena Corvacho}

Construct-LFC, Faculty of Engineering, Civil Engineering Department, Laboratory of Building Physics, University of Porto R. Dr. Roberto Frias, 4200-465, Porto (Portugal)

corvacho@fe.up.pt

https://orcid.org/0000-0002-0398-3423

\author{
Manuscript Code: 14496 \\ Date of Acceptance/Reception: 26.02.2021/28.05.2020 \\ DOI: 10.7764/RDLC.20.1.106
}

\begin{abstract}
In this paper, some of the results of an experimental study are presented. Its purpose was to better understand the impact of glazing on thermal comfort of users of indoor spaces (living and working), especially in the areas near glazed walls. Glazed elements, such as windows and glazed doors, allow visual access to the outdoor environment and the entrance of natural light and solar heat gains but they are often the cause of unwanted heat losses and gains and are disturbing elements in obtaining thermal comfort, both in global terms and in what concerns local discomfort due to radiant asymmetries and/or air draughts. Furthermore, solar radiation directly affecting users in the vicinity of glazing can also cause discomfort. These disturbances are recognized by users, both on cold winter days and on hot summer days. To assess thermal comfort or thermal neutrality of a person in a particular indoor space, it is important to know their location within that space. Thus, in order to adequately assess thermal comfort in the areas near the glazing, the indoor thermal environment must be characterized for this specific location. In this study, two indoor spaces (a classroom and an office-room) of a school building were monitored at different periods of the year. The measurements of the environmental parameters were performed both in the center of the rooms and in the areas near the glazing. Five models of thermal comfort assessment were then applied to the results, in order to compare the comfort conditions between the two studied locations and to evaluate the applicability of these models to the areas close to glazed walls. It was observed there was clearly a greater variability of comfort conditions in the vicinity of the glazed walls when compared to the center of the rooms. The application of thermal comfort assessment models to the two studied rooms was able to reveal the differences between the two compared locations within each space. It was also possible to show the effect of incoming solar radiation and the influence of the geometry of the spaces and of the ratio between glazed area and floor area by comparing the results for both spaces. The assessment model proposed by LNEC (Portuguese National Laboratory of Civil Engineering) proved to be the most adapted to Portuguese users' habits.
\end{abstract}

Keywords: thermal comfort asessment models, glazing, on site measurements.

\section{Introduction}

According to the available information (DGEG/ADENE, 2020), energy consumption in the building sector in Portugal (residential and non-residential sectors) represented 31.9\% of total final energy consumption, in 2018. In the same year, the share of different energy sources in buildings was the following (DGEG/ADENE, 2020):

- In residential buildings: oil, 13\%; natural gas, 9\%; electricity, $40 \%$; biomass, 27\%; solar thermal, $2 \%$; renewable part of heat pumps energy consumption, $9 \%$ (this share corresponds to $58 \%$ of renewable energy, since $55 \%$ of electricity produced in 2018 was of renewable origin);

- In non-residential buildings: oil, 6\%; natural gas, $11 \%$; electricity, $60 \%$; renewable part of heat pumps energy consumption (only for heating), 16\%; others, $5 \%$ (this share corresponds to about $50 \%$ of renewable energy).

The improvement of the thermal performance characteristics of buildings is highly recommended and pursued especially from the perspective of energy conservation, but also to allow the maintenance and enhancement of other advantages such as greater durability of the building and better conditions of thermal comfort. It is also important to promote and encourage the use of low energy strategies, such as passive heating and cooling (Matias, 2010). It can be said that the success of a building depends on a comfortable indoor environment achieved without increasing the use of energy. Although the general definitions given to thermal comfort have been the subject of somehow philosophical inquiry and debate, they do not fail to emphasize that the comfort sensation is influenced by a combination of physical, psychological and physiological factors. In general, comfort is achieved when body temperature is maintained within a narrow range, skin moisture is low, and physiological regulation effort is minimal (Fanger, 1970). 
This is the basis for the proposals of thermal comfort indexes for assessing indoor thermal environments, such as the predicted mean vote (PMV) developed by Fanger. To meet the aesthetic, daylighting and access to the outdoor environment requirements, glazed elements (windows and glazed doors, glass curtain wall, glass dome, and skylight) are more and more widely used in modern buildings. Indoor thermal comfort in such buildings depends greatly on the direct component of solar radiation. There is a need to evaluate the influence of this radiant energy on the thermal balance of the human body. At present there is a lack in calculation tools with this purpose. Significant efforts have been made worldwide to minimize energy consumption by promoting the use of simulation tools for the analysis of thermal performance of buildings. Thus, the improvement of the accuracy of mathematical models is also of paramount importance, in order to take also into account the effect of incoming solar radiation on users thermal comfort. With the aim of satisfying this need, some studies were developed and evaluation methods were proposed, namely:

- A simple method for the evaluation of the mean radiant temperature (Tmr) for a human subject placed in a confined environment, and irradiated by solar radiation, direct as well as diffuse (La Gennusa et al., 2005);

- A model for managing and evaluating solar radiation for indoor thermal comfort (La Gennusa et al., 2007);

- A corrected predicted mean vote (CPMV) index to evaluate thermal environment of buildings with solar radiation (Zhang et al., 2018);

- The SolarCal model, which computes an increase in Mean Radiant Temperature (Tmr) equivalent to shortwave gains from direct, diffuse, and indoor-reflected radiation on a person (Arens et al., 2015).

Some other examples can be given of studies that have taken into account the effect of direct incident solar radiation (Bessoudo et al., 2007; Bessoudo et al., 2010; Tzempelikos et al. 2010; Tzempelikos et al. 2007; Tzempelikos et al. 2010; Huizenga et al., 2006; Serra et al., 2010; Poirazis, 2008; Singh et al., 2008; Augusto et al., 2007). They highlight the importance of including the effect of solar radiation when assessing thermal comfort in perimeter zones and demonstrate the ability of shading devices to improve thermal comfort conditions near a highly glazed façade, concluding:

- The solar radiation that directly affects the user can also cause discomfort (La Gennusa et al., 2007);

- Shading devices, which are normally used to improve visual comfort (dazzle control), depending on their size and type and on their suitability to the orientation of the façade, can also improve thermal comfort conditions in areas near glazing (Arens et al., 2015; Bessoudo et al., 2007; Serra et al., 2010);

- In cold and sunny conditions, shading devices may improve the thermal environment by decreasing Radiant Temperature Asymmetry (RTA) due to direct solar radiation and maintaining the Operative Temperature (Top) of the space within the comfort zone for most of the day (Bessoudo et al., 2007; Bessoudo et al., 2010; Tzempelikos et al. 2007; Tzempelikos et al. 2010);

- For cloudy days, the differences in thermal comfort conditions between using and not using a shading device are less apparent, however using it could still reduce the amount of heat gains through the façade (Tzempelikos et al. 2007; Tzempelikos et al. 2010);

- In summer, window surface temperatures are often higher than indoor air temperature, causing discomfort due to heat gains by radiation from the window and also high Radiant Temperature Asymmetry (RTA) (Tzempelikos et al. 2007; Singh et al., 2008);

- The long-wave exchange between the body and the window is the most significant exchange except for the case where the body is in direct sun, in which case the impact solar load can be more significant. For most residentialsize windows, draft effects exist but are typically small (Huizenga et al., 2006);

- The energy efficiency of the façade and the thermal comfort implications can be evaluated considering the ability to pre-heat the ventilation air in the winter season, and the ability to remove part of the solar load during the summer season (Serra et al., 2010);

- In fully glazed buildings, the risk of comfort problems is higher, especially in cases when windows with high thermal and solar transmittance are applied. The variation in operative temperatures increases, leading to an unacceptable thermal environment (Poirazis, 2008);

- The simplification of the long-wave radiation heat transfer calculation, using a geometrical factor the so-called view factor, may implicate several errors on the evaluation of the internal surface temperatures that can cause discrepancies on the prediction of thermal comfort level and energy consumption, mainly when surfaces present complex geometries, openings (windows and doors) and when there are obstructions between them (Augusto et al., 2007).

Most of the research on the effect of solar radiation on indoor thermal comfort assumes a steady state model for the hygrothermal conditions, whereas in fact, the hygrothermal environment in the vicinity of glazing is highly transient 
(Bessoudo et al., 2010; Zhang, 2003). In last years, thermal comfort models have been integrated into operations regulatory documents and research methods of thermal comfort were proposed (Zhang, 2003; Carlucci et al. 2018). In the present study an evaluation of the applicability of thermal comfort assessment models at the center of the spaces and in areas near glazing is performed. This paper analyzes the PMV and PPD Indices (Fanger, 1970; EN ISO 7730, 2005), models in ANSI/ASHRAE 55 (2010), the EN 15251 (2007) and a Model Proposed by LNEC (Portuguese National Laboratory for Civil Engineering) (Matias, 2010).

State of the art

\section{Scope}

In this experimental evaluation, it is intended to characterize the thermal comfort conditions, at the center of the indoor spaces and at the areas near glazed walls, in a non-residential building, with a non-air-conditioned indoor environment and with natural ventilation. Based on the measured values of hygrothermal parameters, known thermal comfort assessment models were applied.

\section{PMV and PPD indices}

The predicted mean vote (PMV) index corresponds to the average expected value of the vote in the thermal sensation scale of the users of an indoor space and the predicted percentage of dissatisfied (PPD) index gives a prediction of the percentage of people who perceives that indoor environment as uncomfortable (Fanger, 1970). To determine the PMV index, several variables must be considered, namely: metabolic rate (M), effective mechanical mower (W), clothing insulation ( $(\mathrm{cl})$, air temperature (Ta), mean radiant temperature (Tmr), air speed (va), water vapour partial pressure (Pa) (EN ISO 7730, 2005). The scale of thermal sensation consists of seven values, ranging from -3 (Cold) to +3 (Hot), in which the zero represents the thermal neutrality (figure 1). Three categories of thermal environment are defined in EN ISO 7730 (2005): category A (PPD $<6 \%$ and $-0,2<$ PMV $<+0,2$ ), category $B$ (PPD $<10 \%$ and $-0,5<$ PMV $<+0,5$ ) and category C (PPD $<15 \%$ and $-0,7<P M V<+0,7$ ). In a closed environment, people exposed to a given combination of variables are considered to be in acceptable thermal comfort conditions if the PMV value is between -0.5 and +0.5 and the PPD value is less than 10\% (ANSI/ASHRAE Standard 55, 2010).

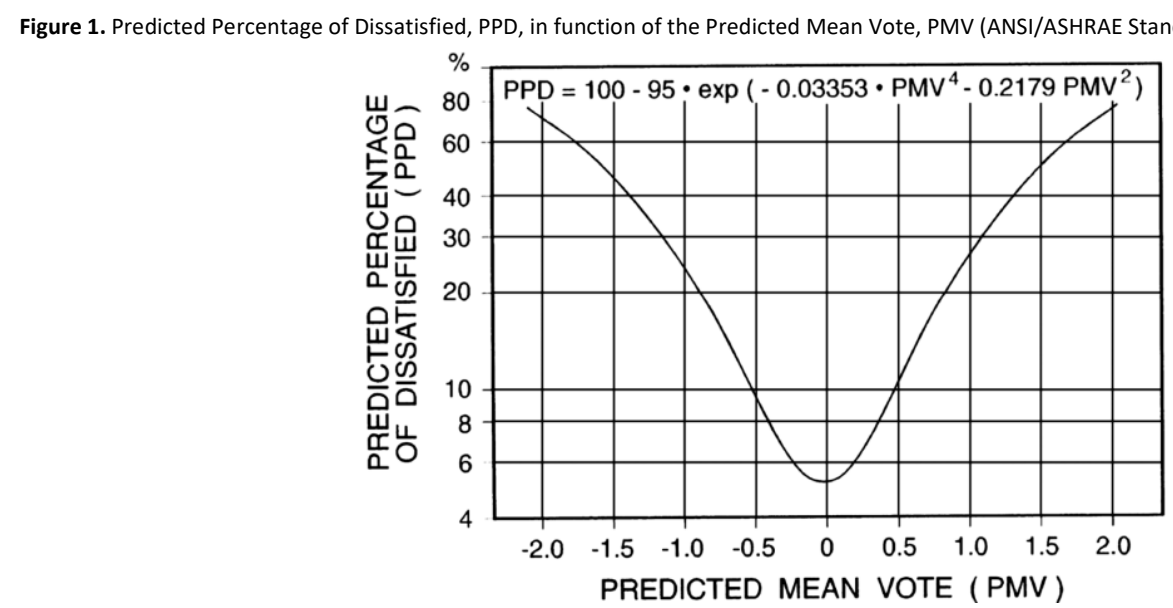

\section{Operative temperature}

The Operative temperature concept is another way of evaluating thermal comfort and resulted from the recognition of the importance, for comfort conditions, of thermal radiation exchanges from and to the surrounding surfaces. The operative temperature (Top) simultaneously encompasses the effects of three variables that influence comfort: air temperature ( $\mathrm{Ta}$ ), mean radiant temperature ( $\mathrm{Tmr}$ ) and air speed (va). From its definition, the operative temperature can be expressed as follows (EN ISO 7730, 2005):

$$
T_{o p}=\frac{T_{a} \cdot \sqrt{10 \cdot \mathrm{v}_{a}}+T_{m r}}{1+\sqrt{10 . \mathrm{v}_{a}}}
$$


The most common methods for determining the mean radiant temperature are direct measurements (usually of the globe temperature as measured by a black globe with a temperature sensor at its center) (Bessoudo et al., 2010) and the calculation using the surface temperatures of the envelope and the value of the view factor of each surface (opaque and glazed) in relation to the user (La Gennusa et al., 2005; Bessoudo et al., 2007; Augusto et al., 2007). In indoor environments where va is less than $0.2 \mathrm{~m} / \mathrm{s}$ or the difference between $\mathrm{Tmr}$ and $\mathrm{Ta}$ is less than $4{ }^{\circ} \mathrm{C}$, the operative temperature may be calculated as the arithmetic mean of Ta and Tmr (EN ISO 7730, 2005).

\section{Standards and model proposed by LNEC}

PMV and PPD indices and the Operative Temperature concept have been used by internationally recognized standards currently in force, namely EN ISO 7730 (2005) and ANSI/ASHRAE 55 (2010), which set out recommendations for acceptable thermal comfort conditions. More recently, European standard EN 15251 (2007) adopted the recommendations specified in EN ISO 7730 (2005) for air-conditioned buildings and an adaptive model for non-airconditioned buildings. An adaptive model addresses the issue of thermal comfort within buildings in a dynamic regime in which the user can interact physically and psychologically with the surrounding thermal environment.

The ANSI/ASHRAE 55 (2010) standard proposes a graphic comfort zone method, shown in figure 2 (on the left), to assess thermal comfort which considers operative temperature and humidity, applicable to environments with an air speed below $0.2 \mathrm{~m} / \mathrm{s}$, in which users' activities are mainly sedentary (1.0 to $1.3 \mathrm{met}$ ) and their clothing has a thermal resistance of 0.5 to 1.0 clo, for summer and winter conditions, respectively. The comfort zones were defined assuming that $80 \%$ of the users are satisfied with the thermal environment of the space. This limit of $80 \%$ corresponds to the acceptable thermal comfort conditions defined for PMV indices of -0.5 to +0.5 and PPD $<10 \%$, plus an additional $10 \%$ dissatisfaction that may occur on average due to local thermal discomfort.

For non-air-conditioned indoor environments and where the users can freely adapt their clothing to environment conditions, ANSI/ASHRAE 55 (2010) also provides an adaptive model, based on the work developed by de Dear et al. (1997). The ANSI/ASHRAE 55 (2010) adaptive model considers the acceptable operative temperature range shown in figure 2 (on the right) as a function of the mean monthly outdoor air temperature between $10^{\circ} \mathrm{C}$ and $33.5^{\circ} \mathrm{C}$ and user activity levels between 1.0 and 1.3 met. If the mean monthly outdoor air temperature is outside this range, mechanical heating or cooling systems have to be installed.

Figure 2. a) graphic comfort zone method for the assessment of thermal comfort as a function of Operative Temperature and humidity adapted from ANSI/ASHRAE 55 (2010); b) adaptive thermal comfort assessment model (ANSI/ASHRAE Standard 55, 2010). (Self-Elaboration).
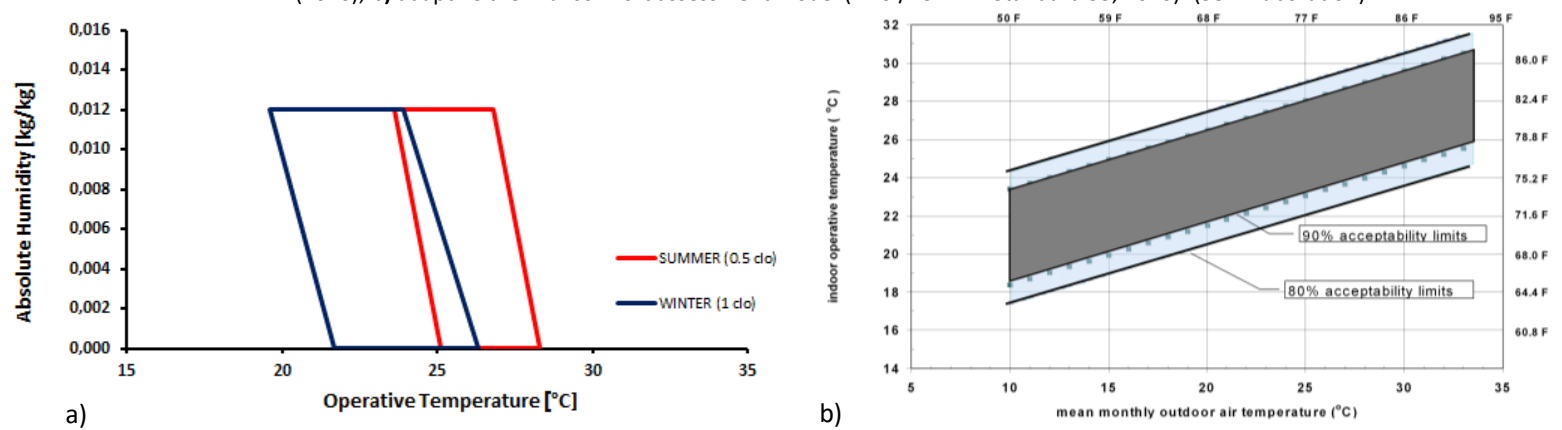

EN 15251 (2007) proposes an adaptive model, presented in figure 3, which defines an acceptable operative temperature range for the summer, for the design of non-residential buildings with no mechanical cooling system, divided into four categories of comfort: category I - PPD $<6 \%$ and $-0.2<$ PMV $<+0.2$; category II - PPD $<10 \%$ and $-0,5<$ PMV $<+0,5$; category III - PPD $<15 \%$ and $-0.7<$ PMV $<+0.7$ and category IV - PPD $>15 \%$ and PMV $<-0.7$ or PMV $>+0.7$, as a function of the exponentially weighted running mean of the daily outdoor temperature, Trm, calculated with the daily mean outdoor air temperature of the previous days Tn-i, according to equation (2), Reflecting more realistically the changes meteorological conditions and their impact on indoor comfort conditions (EN 15251, 2007; Nicol \& Humphreys, 2009).

$$
T_{r m}=\frac{\left(T_{n-1}+0.8 T_{n-2}+0.6 T_{n-3}+0.5 T_{n-4}+0.4 T_{n-5}+0.3 T_{n-6}+0.2 T_{n-7}\right)}{3.8}
$$

Also in this standard, the activities of the users are considered mainly sedentary (1.0 to 1.3 met) and their clothing with a thermal resistance between 0.5 and $1.0 \mathrm{clo}$, for summer and winter respectively. Comfort categories are defined according to the recommended PMV and PPD indices for air-conditioned buildings.

The values of the operative temperature to be considered are dependent on the type of building, the thermal resistance of the clothing and the metabolic rate (activity of the user) and not dependent on the outdoor thermal conditions, for 
this temperature range, assuming that in winter, whether or not the building has a mechanical cooling system, it will always have an active heating system (Nicol \& Humphreys, 2009; Nicol \& Humphreys, 2010).

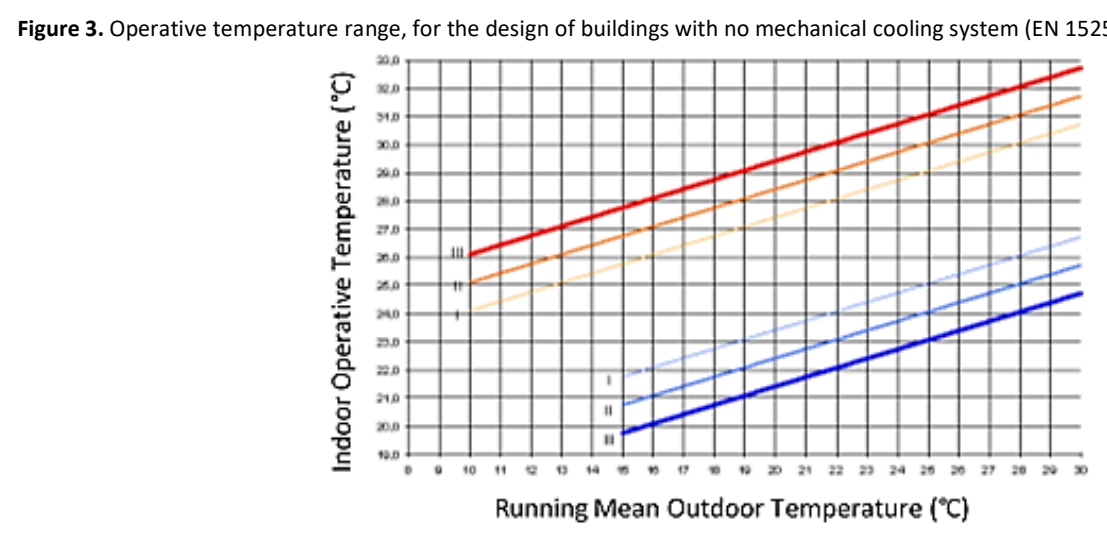

After an experimental study by Luís Matias (Matias, 2010), which included in-situ measurements of thermal comfort parameters and the conduction of user surveys for further comparison, the Portuguese National Laboratory of Civil Engineering (LNEC) proposed a model for thermal comfort assessment. The proposed model was based on the analysis of the results obtained in an extensive set of surveys of indoor environment conditions, carried out in Portuguese residential and non-residential buildings, and on the thermal perception expressed by the respective users (Matias $\&$ Pina dos Santos, 2013). This study allowed the definition of two patterns of comfort temperature, Tconf, defined as a function of the running mean outdoor temperature, one to be applied in spaces with conditioning systems ON and another in spaces with conditioning systems OFF. It includes a comfort zone for an acceptability of $90 \%$ defined as \pm 3 ${ }^{\circ} \mathrm{C}$ around the comfort temperature. The comfort temperature is obtained from Trm calculated with the daily mean outdoor air temperature of the previous days $\mathrm{Tn}-\mathrm{i}$, according to equation (2).

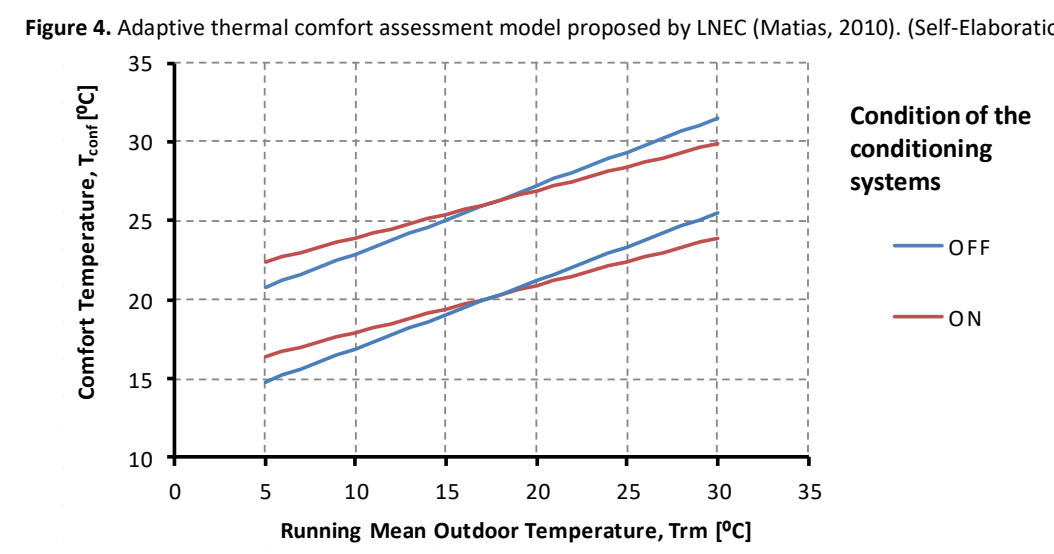

The use of adaptive methodologies to evaluate thermal comfort conditions of an indoor space makes perfect sense since users can change the conditions of the surroundings and sometimes their location and clothing. The great difficulty is associated with the establishment of the limits to be considered, which can hardly be expected to be the same for different sociocultural realities. People's capacity for adaptation to certain thermal conditions varies considerably, being strongly influenced by their habits (resulting to a great extent from the local climate but also from cultural, social and economic conditions) by their age and their state of health (de Dear et al., 1997; Nicol \& Humphreys, 2010). Therefore, the generalization of a methodology can be a somewhat complex task. In this study the three adaptive thermal comfort models described above were used, the model referred to in ANSI/ASHRAE 55 (2010), the model proposed by EN 15251 (2007) and the model proposed by LNEC (Matias, 2010).

Material and methods

\section{Goals of the on site study}

The on site study presented below was carried out in order to assess thermal comfort conditions in the center of indoor spaces and in areas near glazed façades, taking into account the geometry of the rooms, the location of glazing and the percentage of glazed area, the use of shading and solar protection devices and the opening thereof, for summer, winter and mid-season conditions. In order to assess thermal comfort, PMV and PPD indices and the Graphic Comfort Zone 
Method proposed by ANSI/ASHRAE 55 (2010) are applied to the measured values, as well as the adaptive comfort models recommended by ANSI/ASHRAE 55 (2010) and EN 15251 (2007) and proposed by LNEC (Matias, 2010). A series of experimental campaigns measuring relevant parameters were delineated in two different indoor spaces, from July 2012 to June 2013: Summer Campaign - July 27 to September 14; Autumn Campaign - September 21 to December 20; winter campaign - December 21 to March 20 and Spring Campaign - March 21 to June 20. Measurement campaigns consisted of a continuous monitoring of hygrothermal parameters and on discontinuous measurements of ventilation airflow (Oliveira, 2016).

This on site study was carried out in two rooms, a classroom and an office-room, of the School of Technology and Management of the Polytechnic Institute of Viseu (ESTGV - IPV, located in the central northern region of Portugal) under different measurement conditions. In Viseu, the summers are short, warm, dry, and mostly clear and the winters are cold, wet, and partly cloudy. Over the course of the year, the temperature typically varies from $2{ }^{\circ} \mathrm{C}$ to $29^{\circ} \mathrm{C}$ and is rarely below $-3{ }^{\circ} \mathrm{C}$ or above $34^{\circ} \mathrm{C}$. The main specific objectives of the study were to evaluate:

- Thermal comfort conditions at the center of the spaces and in the areas near the glazing;

- The applicability of thermal comfort assessment models;

- The effect of incoming solar radiation at indoor spaces;

- The effect of the geometry of the spaces and of the ratio between glazed area and floor area.

In addition, it was possible to evaluate the effect of an existing horizontal overhang above the classroom window.

\section{Case study and measurements}

As previously mentioned, the on site study was carried out in a classroom and an office-room of ESTGV - IPV. Their plans are presented in figure 5 . The buildings where the studied rooms are located were built in the 1990s (main orientation $\mathrm{SE} / \mathrm{NW}$ ). The exterior walls are double walls with thermal insulation in the air cavity. The roofs are flat roofs with the waterproofing membrane beneath thermal insulation (inverted roof). The ventilation of the indoor spaces is mainly natural. Figure 5 shows part of the SW façades of the buildings with the locations of the monitored rooms marked. Table 1 gives a general characterization of the studied rooms.

Table 1. General features of the studied rooms. (Self-Elaboration).

\begin{tabular}{|c|c|c|}
\hline & Classroom (CR) & Office-room (OR) \\
\hline Floor & \multicolumn{2}{|l|}{$2^{\text {nd }}$} \\
\hline Area & $61.10 \mathrm{~m}^{2}$ & $22.80 \mathrm{~m}^{2}$ \\
\hline Depth & $6.37 \mathrm{~m}$ & $3.40 \mathrm{~m}$ \\
\hline Height & $3.20 \mathrm{~m}$ & $3.10 \mathrm{~m}$ \\
\hline $\begin{array}{l}\text { Number of glazed } \\
\text { openings }\end{array}$ & 2 & 1 \\
\hline Type of glass & \multicolumn{2}{|c|}{ Double $(6+10+4 \mathrm{~mm})$} \\
\hline Frame & \multicolumn{2}{|c|}{ Aluminum } \\
\hline $\begin{array}{l}\text { Orientation of the } \\
\text { openings }\end{array}$ & $\begin{array}{c}\text { SW }(210 \circ)-6.60 \mathrm{~m}^{2} \text { (11\% of floor area) } \\
\text { NW (300) - } 3.45 \mathrm{~m}^{2}(5.6 \% \text { of floor } \\
\text { area) }\end{array}$ & $\begin{array}{c}\mathrm{SW}(2109)-8.80 \mathrm{~m}^{2} \text { (35\% of floor } \\
\text { area) }\end{array}$ \\
\hline Solar protection & SW $(2109)$ - indoor venetian blinds & SW (210) - indoor venetian blinds \\
\hline Shading & $\begin{array}{c}\text { SW }(2109) \text { - horizontal device } 1.00 \mathrm{~m} \\
\text { depth } \\
\text { NW - Building body }\end{array}$ & None \\
\hline $\begin{array}{l}\text { Indoor ventilation } \\
\text { specific devices }\end{array}$ & $\begin{array}{l}\text { Air inlet (grill) on the door ( } 54 \times 37.3 \\
\mathrm{~cm})\end{array}$ & None \\
\hline
\end{tabular}



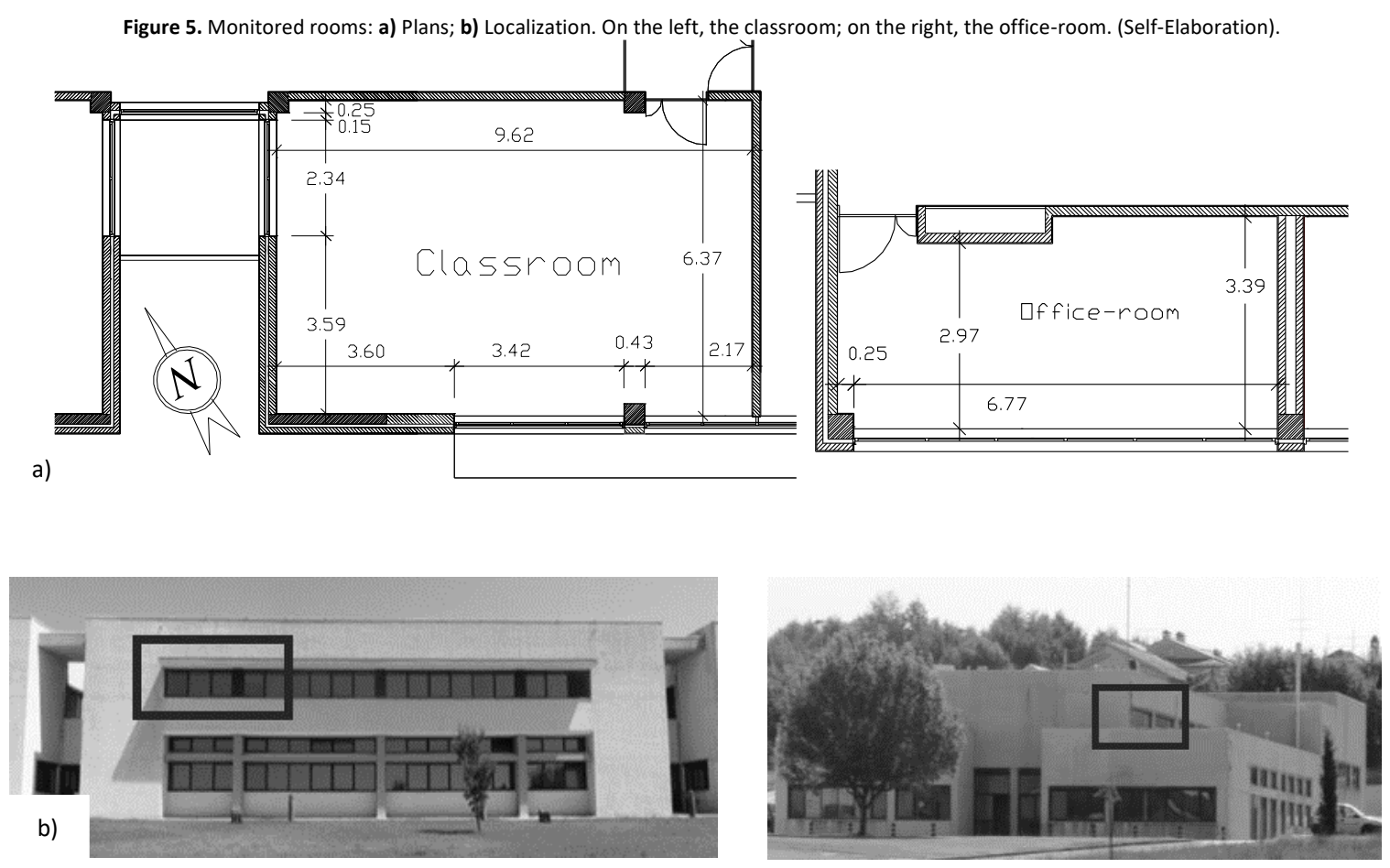

During the measurement campaigns, the outdoor environmental parameters were recorded, with time steps of 3 minutes, namely: the outdoor air temperature; the dew point temperature; the outdoor relative humidity; the speed and direction of the wind; the global solar irradiance on horizontal surface and the atmospheric pressure. For the recording of air temperature and relative humidity a single data logger, Hobo H08-03-02, was used with an accuracy of $\pm 0.7{ }^{\circ} \mathrm{C}$ for temperature measurements and an accuracy of $\pm 5 \%$ for relative humidity measurements. Atmospheric pressure and wind direction and speed were recorded by a weather station installed on site with a resolution of $0.1 \mathrm{~m} / \mathrm{s}$ for the wind speed and $22.5^{\circ}$ for the wind direction. Global solar irradiance on a horizontal surface was recorded by a pyranometer, with sensitivity between 60 and $100 \mu \mathrm{V} / \mathrm{W} / \mathrm{m}^{2}$, connected to a multi-channel data logger.

In what concerns the indoor spaces, environmental parameters were recorded, also with time steps of 3 minutes, using the following portable recording equipment (figure 6): a) Individual data logger Hobo H08-02/3-02 (with an accuracy of $\pm 0.7^{\circ} \mathrm{C}$ for temperature measurements and an accuracy of $\pm 5 \%$ for relative humidity measurements); b) Extension of the individual data-logger Hobo H08-02/3-02 (air temperature between the glazed surface and the blind); c) Indoor microclimatic station "Babuc $A B C$ " (air temperature, globe temperature, relative humidity, air speed, indoor net radiation, radiant asymmetry) - aligned with the center of the glazing and at a distance of $1.20 \mathrm{~m}$ from it; d) Sensor "Fluke 975" for the measurement of air temperature, relative humidity, air speed and $\mathrm{CO}_{2}$ - aligned with the center of the glazing and at a distance of $1.20 \mathrm{~m}$ from it, e) Flowmeters (heat flow), f) Type T thermocouples and multi-channel data logger "Mikromec ${ }^{(R)}$ Multisens" (surface temperature), g) Individual data logger Hobo U12-012 (with an accuracy of $\pm 0.35{ }^{\circ} \mathrm{C}$ for temperature measurements and an accuracy of $\pm 2.5 \%$ for relative humidity measurements) and $\mathrm{h}$ ) Temperature and humidity probe connected to the multi-channel data logger, located in the center of the space.

The individual data loggers for temperature and relative humidity measurements, the microclimatic station and the sensor shown in Figure 6 were placed at a height of $1.10 \mathrm{~m}$ from the floor, as specified in EN ISO 7726 (2001).

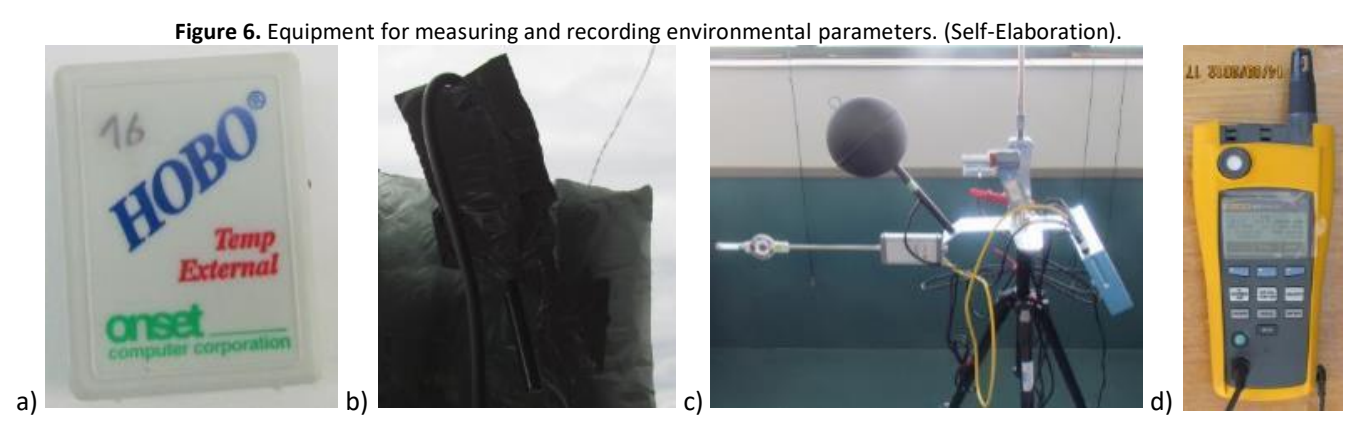



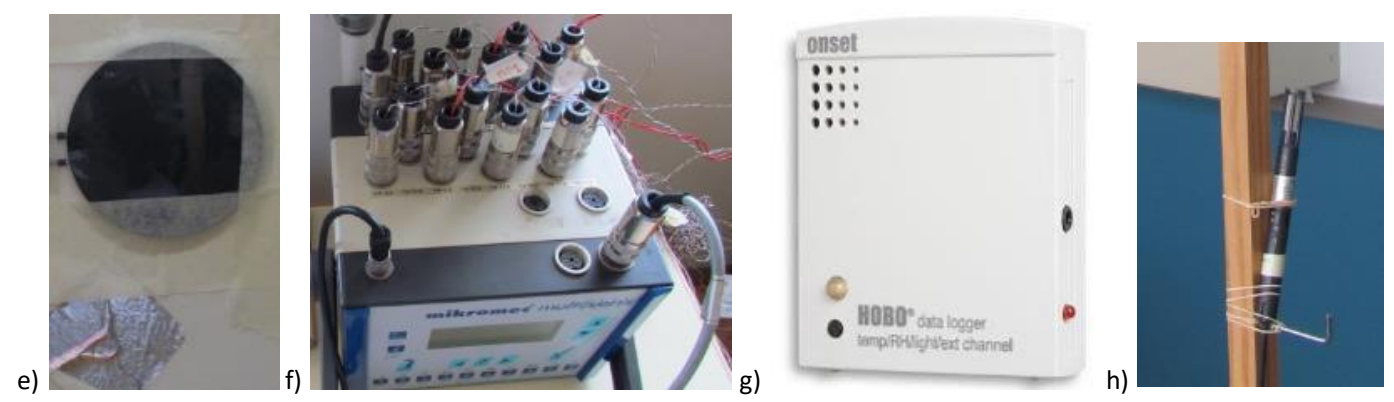

During the measurement campaigns a number of different conditions were considered regarding the solar protection of the glazing, through the use of the indoor Venetian blinds, and regarding the circulation of indoor air by means of the opening of the windows (pivoting of the movable parts of the glazing, corresponding to an effective opening area of $0.36 \mathrm{~m}^{2}$ each) and through the use of two $30 \mathrm{~W}$ fans in each space. Tables 2 and 3 show the measurement conditions and time periods. The analysis of the results distinguishes two different situations related to the availability of solar radiation: clear or overcast sky, except for the Summer Campaign in which there was always a clear sky. In what concerns indoor conditions, the heating system was either ON or OFF. Table 4 shows the operation of the heating system, central system running on natural gas, between November 12 and April 5. In the classroom, between October 20 and April 12 , an average occupancy density of 0.13 users $/ \mathrm{m}^{2}$ was observed on weekdays from 08:00 to 13:00 and from 14:00 to 18:00. The office-room had no occupancy.

\begin{tabular}{|c|c|c|c|}
\hline \multicolumn{2}{|c|}{ Campaign } & Measurement conditions & Time periods \\
\hline \multirow{6}{*}{ Summer } & S1 & Blind $0 \%$ & 31 July to 02 August (1) \\
\hline & $\mathrm{S} 2$ & Blind $100 \%\left(0^{\circ}\right)$ & 04 to 05 August (1) \\
\hline & \multirow{2}{*}{ S3 } & \multirow{2}{*}{ Blind $100 \%\left(0^{\circ}\right)(2 \mathrm{~F})$} & 19 to 20 August (1) - Classroom \\
\hline & & & 15 to 16 August (1) - Office-room \\
\hline & S4 & Blind $100 \%\left(0^{\circ}\right)(\mathrm{W})^{*}$ & 22 to 23 August (1) \\
\hline & S5 & Blind $100 \%\left(90^{\circ}\right)$ & 29 to 30 August (1) \\
\hline \multirow{10}{*}{ Autumn } & \multirow{2}{*}{ A1 } & \multirow{2}{*}{ Blind 0\% (OFF) } & 02 to 04 October (1) \\
\hline & & & 16 to 18 October (2) \\
\hline & \multirow{2}{*}{$\mathrm{A} 2$} & \multirow{2}{*}{$\begin{array}{l}\text { Blind } 100 \%\left(90^{\circ}\right)(\mathrm{OFF}) \\
\text { (O) }\end{array}$} & 26 Oct. to 01 November (1) \\
\hline & & & 03 to 04 November (2) \\
\hline & \multirow{2}{*}{ A3 } & \multirow{2}{*}{ Blind $100 \%\left(90^{\circ}\right)(\mathrm{ON})(\mathrm{O})$} & 12 to 14 November (1) \\
\hline & & & 15 to 17 November (2) \\
\hline & \multirow{2}{*}{ A4 } & \multirow{2}{*}{ Blind $100 \%\left(0^{\circ}\right)(\mathrm{ON})(\mathrm{O})$} & 26 to 27 November (1) \\
\hline & & & 23 to 25 November (2) \\
\hline & \multirow{2}{*}{ A5 } & \multirow{2}{*}{ Blind $0 \%(O N)(O)$} & 28 to 30 November (1) \\
\hline & & & 13 to 18 December (2) \\
\hline
\end{tabular}

Blind - Indoor Venetian blind; Blind 0\% - blind totally open; Blind 100\% - blind totally closed; $\left(0^{\circ}\right)$ Blind with the slats in horizontal position; $\left(90^{\circ}\right)$ Blind with the slats in vertical position; (2F) two fans of $30 \mathrm{~W}$; (W) Pivoting windows open $\left(^{*}\right.$ $4 \mathrm{~W}$ in the classroom and $2 \mathrm{~W}$ in the office-room); (ON) or (OFF) Heating system ON or OFF; (O) Classroom occupied; (1) Clear sky; (2) Overcast sky. 


\begin{tabular}{|c|c|c|c|}
\hline \multicolumn{2}{|c|}{ Campaign } & Measurement conditions & Time periods \\
\hline \multirow{14}{*}{ Winter } & \multirow{2}{*}{ W1 } & \multirow{2}{*}{ Blind $0 \%$ (OFF) } & 27 to 29 December (1) \\
\hline & & & 30 Dec. to 01 Jan (2) \\
\hline & \multirow{2}{*}{ W2 } & \multirow{2}{*}{ Blind $100 \%\left(90^{\circ}\right)(\mathrm{ON})(\mathrm{O})$} & 04 to 06 January (1) \\
\hline & & & 07 to 09 January (2) \\
\hline & \multirow{2}{*}{ W3 } & \multirow{2}{*}{ Blind $100 \%\left(0^{\circ}\right)(\mathrm{ON})(\mathrm{O})$} & 10 to 15 January (1) \\
\hline & & & 16 to 17 January (2) \\
\hline & \multirow{2}{*}{ W4 } & \multirow{2}{*}{ Blind $100 \%\left(0^{\circ}\right)(\mathrm{ON})(\mathrm{O})$} & 21 to 22 January (1) \\
\hline & & & 18 to 20 January (2) \\
\hline & \multirow{2}{*}{ W5 } & \multirow{2}{*}{ Blind $100 \%\left(90^{\circ}\right)(\mathrm{ON})(\mathrm{O})$} & 03 to 09 February (1) \\
\hline & & & 10 February (2) \\
\hline & \multirow{2}{*}{ W6 } & \multirow{2}{*}{ Blind $100 \%\left(45^{\circ}\right)(\mathrm{ON})(\mathrm{O})$} & 21 to 25 February (1) \\
\hline & & & 17 February (2) \\
\hline & \multirow{2}{*}{ W7 } & \multirow{2}{*}{ Blind $0 \%(O N)(O)$} & 09 to 15 March (1) \\
\hline & & & 03 to 07 March (2) \\
\hline \multirow{13}{*}{ Spring } & \multirow{2}{*}{ SP1 } & \multirow{2}{*}{ Blind $0 \%(O N) *$} & 22 to 24 March (1) \\
\hline & & & 25 to 27 March (2) \\
\hline & \multirow{2}{*}{ SP2 } & \multirow{2}{*}{ Blind $100 \%\left(90^{\circ}\right)$ (OFF) } & 13 to 15 April (1) \\
\hline & & & 07 to 12 April (2) \\
\hline & SP3 & Blind $100 \%\left(0^{\circ}\right)(\mathrm{OFF})$ & 23 to 28 April (1) \\
\hline & \multirow{2}{*}{ SP4 } & \multirow{2}{*}{ Blind $100 \%\left(45^{\circ}\right)(\mathrm{OFF})$} & 01 to 05 May (1) \\
\hline & & & 06 to 09 May (2) \\
\hline & \multirow{2}{*}{ SP5 } & \multirow{2}{*}{ Blind $0 \%(2 W)(O F F)$} & 21 to 25 May (1) \\
\hline & & & 16 to 19 May (2) \\
\hline & \multirow{2}{*}{ SP6 } & \multirow{2}{*}{ Blind $100 \%\left(0^{\circ}\right)(2 \mathrm{~W})(\mathrm{OFF})$} & 31 May to 05 June (1) \\
\hline & & & 07 to 10 June (2) \\
\hline & \multirow{2}{*}{ SP7 } & \multirow{2}{*}{ Blind $100 \%\left(90^{\circ}\right)(2 \mathrm{~W})(\mathrm{OFF})$} & 12 to 16 June (1) \\
\hline & & & 17 to 19 June (2) \\
\hline
\end{tabular}

Blind - Indoor Venetian blind; Blind 0\% - blind totally open; Blind 100\% - blind totally closed; $\left(0^{\circ}\right)$ Blind with the slats in horizontal position; $\left(90^{\circ}\right.$ ) Blind with the slats in vertical position; (W) Pivoting windows open; (ON) or (OFF) Heating system ON or OFF (* At SP1 period - system OFF in the classroom and ON in the office-room); (O) Classroom occupied; (1) Clear sky; (2) Overcast sky.

\begin{tabular}{ll}
\multicolumn{3}{c}{ Table 4. Heating Schedule. (Self-Elaboration). } \\
\hline & \multicolumn{1}{c}{ on } \\
\hline Working days & $08: 00-12: 30$ and 13:50 - 24:00 \\
Saturday & $08: 00-13: 00$ \\
Sunday & - \\
Holidays & - \\
\hline
\end{tabular}

The heating system operates as a function of the outdoor temperature and is controlled as a function of the temperature of the water when returning to the boiler. In each space it is possible to turn the radiators ON and OFF manually. The whole experimental campaigns lead to a very large number of results whose full presentation is not possible in a single paper. In order to illustrate the response to the objectives set, some of the results are presented, namely the ones of the first periods of summer and winter campaigns: S1 (first period of summer) and W1 (first period of winter). These two time periods concern situations where the venetian blinds are totally open, allowing the study of the effect of incoming direct solar radiation, the heating system is off, the windows are closed and both spaces are unoccupied.

Results

\section{Air temperature}

In both periods under analysis (S1 and W1), the studied spaces were unoccupied however, the normal schedule of occupation is marked on the graphs (unshaded columns) and the analysis of the results is done, considering only the hours of possible occupation, which would be from 8:00 am to 1:00 pm and from 2:00 pm to 6:00 pm, on week days and from 8:00 am to 1:00 pm, on Saturdays. For Summer Campaign, Figure 7 shows that both the classroom and the 
office-room (but especially this one), under the set conditions, do not guarantee to their users adequate air temperatures. For the possible occupation schedule, the values recorded in the office-room at any of the measuring points are always higher than those recorded outdoors, varying, at a distance of $1.20 \mathrm{~m}$ from the glazing, between 27.87 ${ }^{\circ} \mathrm{C}$ and $32.09{ }^{\circ} \mathrm{C}$. The values of the air temperature (median, maximum and minimum) at $1.20 \mathrm{~m}$ from the glazing are higher than the values recorded at the center of the office-room.

The classroom presents thermal comfort conditions more favorable than the ones in the office-room, with temperature values at $1.20 \mathrm{~m}$ from the glazing varying between $26.60{ }^{\circ} \mathrm{C}$ and $28.00{ }^{\circ} \mathrm{C}$, possibly due to the effect of the horizontal overhang, the lower percentage of glazed area in relation to the floor area, the greater depth of the room and the existence of a ventilation grid. For the classroom the value of the median air temperature registered at $1.20 \mathrm{~m}$ of the glazed window, $27.40^{\circ} \mathrm{C}$, is also slightly higher than the value registered at the center, $27.12^{\circ} \mathrm{C}$.

Figure 7. Indoor air temperature (at the center, $1.20 \mathrm{~m}$ from glazing and close to glazing), outdoor air temperature (outdoor) and global solar irradiance on horizontal surface, during Summer Campaign (S1): a) in the classroom (CR); b) in the office-room (OR). (Self-Elboration).

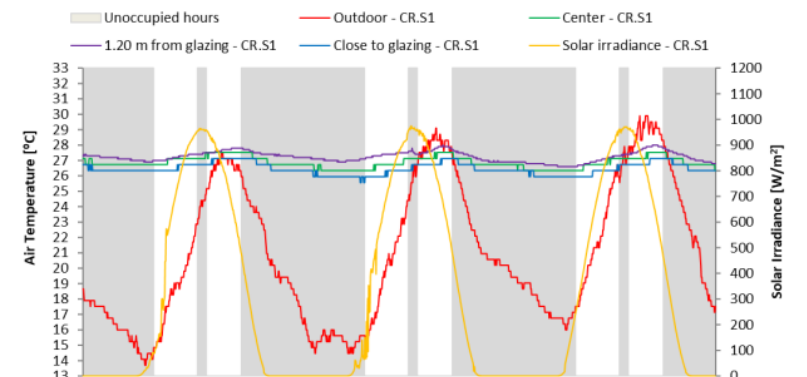

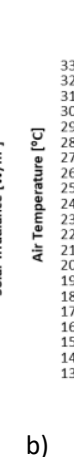

b)

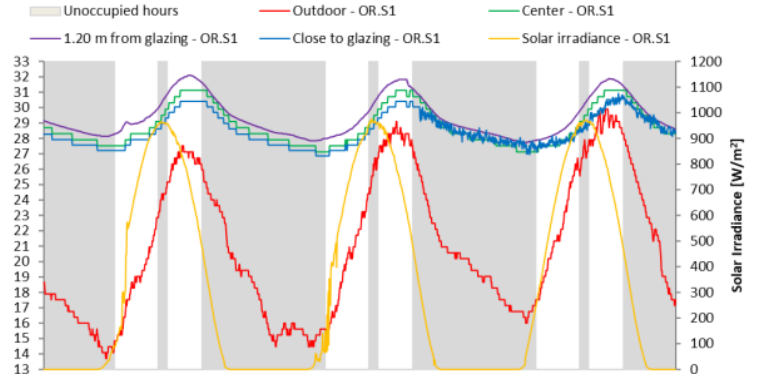

During the winter campaign, in the period under analysis (W1), Figure 8, without using the heating system, in the possible occupation hours thermal comfort conditions are not reached in the case of overcast conditions and, for the situation of clear skies, especially the minimum temperatures are also well below the minimum level of comfort established by Portuguese regulation $\left(18^{\circ} \mathrm{C}\right)$. In terms of median values, for the clear sky situation in the office, the conditions are apparently acceptable however, the variation of temperatures is high. On days of clear sky, since the Sun is in its lower position in the sky and the glazed façade is Southwest oriented, there is direct solar radiation coming in the room and the indoor air temperature reaches a maximum of $24.85^{\circ} \mathrm{C}$.

Figure 8. Indoor air temperature (at the center, $1.20 \mathrm{~m}$ from glazing and close to glazing), outdoor air temperature (outdoor) and global solar irradiance on horizontal surface, during winter campaign (W1), on the left, in the classroom (CR) and on the right, in the office room (OR): a) Clear sky; b) Overcast sky. (Self-Elaboration).
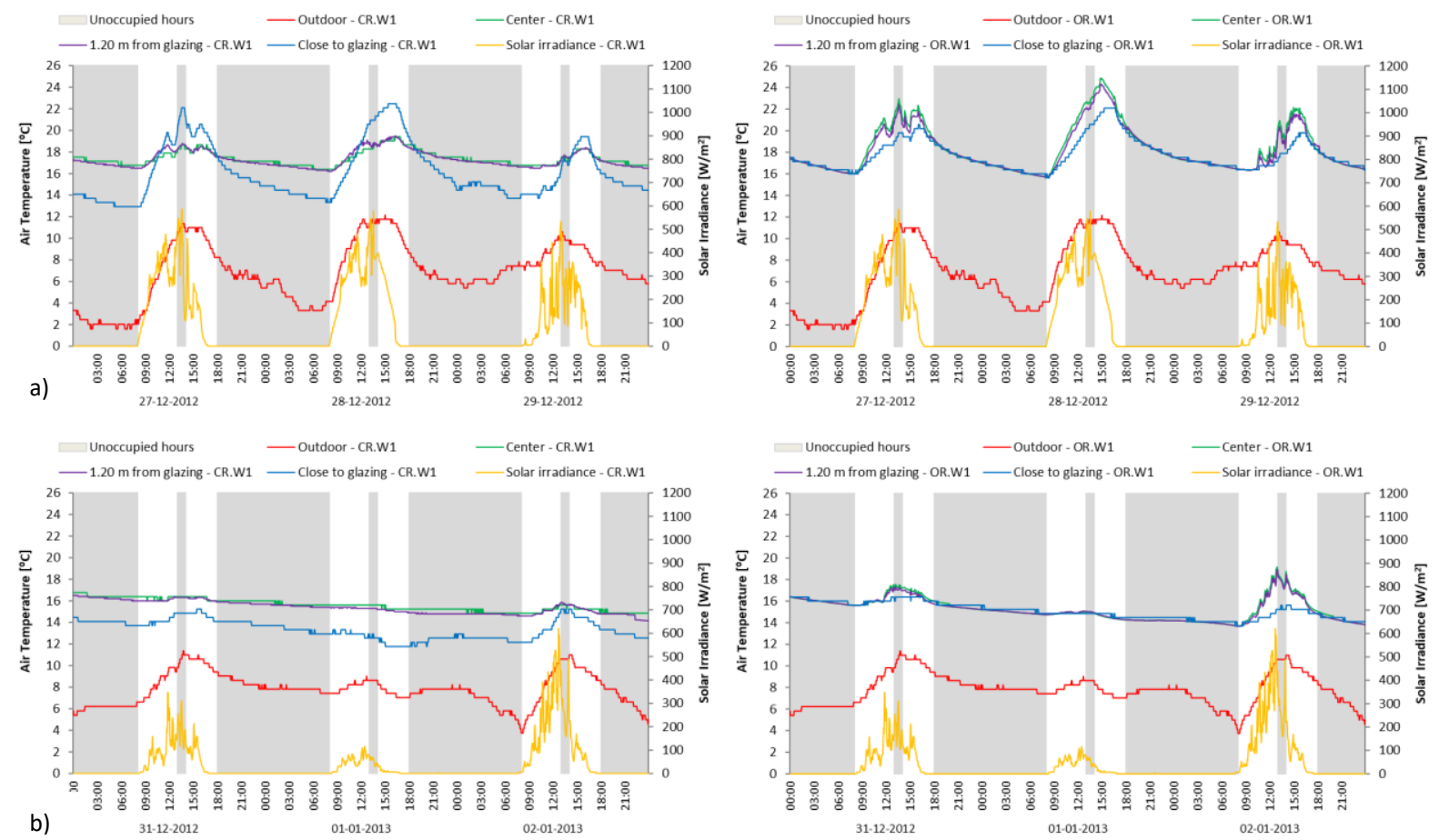
From the analysis of the standard deviation values, in Table 5, it must be noted that the indoor air temperature is generally more variable in the office-room (with no shading devices or solar protection) than in the classroom.

Table 5. Statistical analysis of the indoor air temperature of the first periods of summer and winter campaigns (a). (Self-Elaboration).

\begin{tabular}{|c|c|c|c|c|c|c|c|c|c|}
\hline & & & & \multicolumn{3}{|c|}{ Classroom (CR) } & \multicolumn{3}{|c|}{ Office-room (OR) } \\
\hline \multirow[b]{2}{*}{ Campaign } & \multirow[b]{2}{*}{ Value } & \multirow{2}{*}{$\begin{array}{l}\text { Horizontal } \\
\text { global solar } \\
\text { irradiance } \\
{\left[\mathrm{W} / \mathrm{m}^{2}\right]}\end{array}$} & \multirow[b]{2}{*}{$\begin{array}{l}\text { Outdoor air } \\
\text { temperature }\end{array}$} & \multicolumn{6}{|c|}{ Indoor air temperature $\left[{ }^{\circ} \mathrm{C}\right]$} \\
\hline & & & & Center & $\begin{array}{l}1.20 \mathrm{~m} \\
\text { from } \\
\text { glazing }\end{array}$ & $\begin{array}{l}\text { Close to } \\
\text { glazing }\end{array}$ & Center & $\begin{array}{l}1.20 \mathrm{~m} \\
\text { from } \\
\text { glazing }\end{array}$ & $\begin{array}{l}\text { Close to } \\
\text { glazing }\end{array}$ \\
\hline \multirow{5}{*}{ S1 } & Median & 754.00 & 24.34 & 27.12 & 27.40 & 26.73 & 28.70 & 29.52 & 28.26 \\
\hline & Maximum & 967.00 & 29.90 & 27.52 & 28.00 & 27.12 & 31.12 & 32.09 & 30.92 \\
\hline & Minimum & 65.00 & 14.47 & 26.34 & 26.60 & 25.56 & 27.12 & 27.87 & 26.87 \\
\hline & $\begin{array}{l}\text { Standard } \\
\text { deviation }\end{array}$ & 225.64 & 4.53 & 0.37 & 0.33 & 0.40 & 1.49 & 1.49 & 1.26 \\
\hline & $\begin{array}{c}\text { Coefficient } \\
\text { of Variation } \\
{[\%]}\end{array}$ & 32.24 & 19.35 & 1.35 & 1.22 & 1.50 & 5.10 & 4.98 & 4.37 \\
\hline \multirow{10}{*}{ W1 } & Median & 165.53 & 9.03 & 17.52 & 18.00 & 17.90 & 20.06 & 19.53 & 18.66 \\
\hline & Maximum & 535.37 & 12.16 & 19.42 & 19.50 & 22.48 & 24.85 & 24.30 & 22.09 \\
\hline & Minimum & 0.00 & 2.24 & 16.38 & 16.20 & 12.93 & 15.72 & 15.72 & 15.62 \\
\hline & $\begin{array}{l}\text { Standard } \\
\text { deviation }\end{array}$ & 16.38 & 2.24 & 0.80 & 0.89 & 2.73 & 2.37 & 2.24 & 1.77 \\
\hline & $\begin{array}{l}\text { Coefficient } \\
\text { of Variation }\end{array}$ & 81.03 & 25.63 & 4.54 & 5.04 & 15.47 & 11.97 & 11.57 & 9.59 \\
\hline & Median & 52.40 & 8.23 & 15.62 & 15.40 & 13.70 & 15.61 & 15.61 & 14.85 \\
\hline & Maximum & 621.03 & 10.99 & 16.38 & 16.40 & 15.23 & 19.15 & 18.90 & 16.38 \\
\hline & Minimum & 0.00 & 3.74 & 14.85 & 14.60 & 11.77 & 13.69 & 13.67 & 13.70 \\
\hline & $\begin{array}{l}\text { Standard } \\
\text { deviation }\end{array}$ & 106.98 & 1.54 & 0.51 & 0.51 & 1.03 & 1.14 & 1.05 & 0.72 \\
\hline & $\begin{array}{l}\text { Coefficient } \\
\text { of Variation }\end{array}$ & 128.32 & 18.34 & 3.25 & 3.30 & 7.66 & 7.26 & 6.74 & 4.78 \\
\hline
\end{tabular}

C - Clear sky; O - Overcast sky; (a) Considering only the hours of possible occupation (normal schedule: from 8:00 am to 1:00 pm and from 2:00 pm to 6:00 pm, on week days; from 8:00 am to 1:00 pm, on Saturdays).

Mean radiant temperature and operative temperature

In order to calculate the operative temperature (Top), the mean radiant temperature (Tmr) was determined by two methods: 1) direct measurement (of the globe temperature, measured by a black globe thermometer, connected to the microclimatic station, placed $1.10 \mathrm{~m}$ high); 2) the calculation (using the indoor surface temperatures of the envelope and its respective view factors in relation to a user, at $1.10 \mathrm{~m}$ height, at the center of the space and at $1.20 \mathrm{~m}$ from the glazed window) (La Gennusa et al., 2005; Bessoudo et al., 2007; Augusto et al., 2007; EN ISO 7730, 2005). In the figures 9 and 10, the results for the mean radiant temperature ( $\mathrm{Tmr}$ ) and for the operative temperature (Top), are presented, at $1.10 \mathrm{~m}$ height, at the center of the space and at $1.20 \mathrm{~m}$ from the glazing, in the classroom and at $1.20 \mathrm{~m}$ from the glazing, in the office-room, during summer campaign (S1) and winter campaign (W1), respectively. The variation of the indoor air temperature (Ta), the surface temperature in the center of the glazing (Ts), the outdoor air temperature and the indoor air speed (va) are also presented. 
Figure 9. Mean Radiant Temperature and Operative Temperature: (a-b) in the classroom (CR), at the center of the room (left) and at $1.20 \mathrm{~m}$ from the glazing (right); c) at $1.20 \mathrm{~m}$ from glazing, in the office-room (OR), during Summer Campaign (S1). (Self-Elaboration).
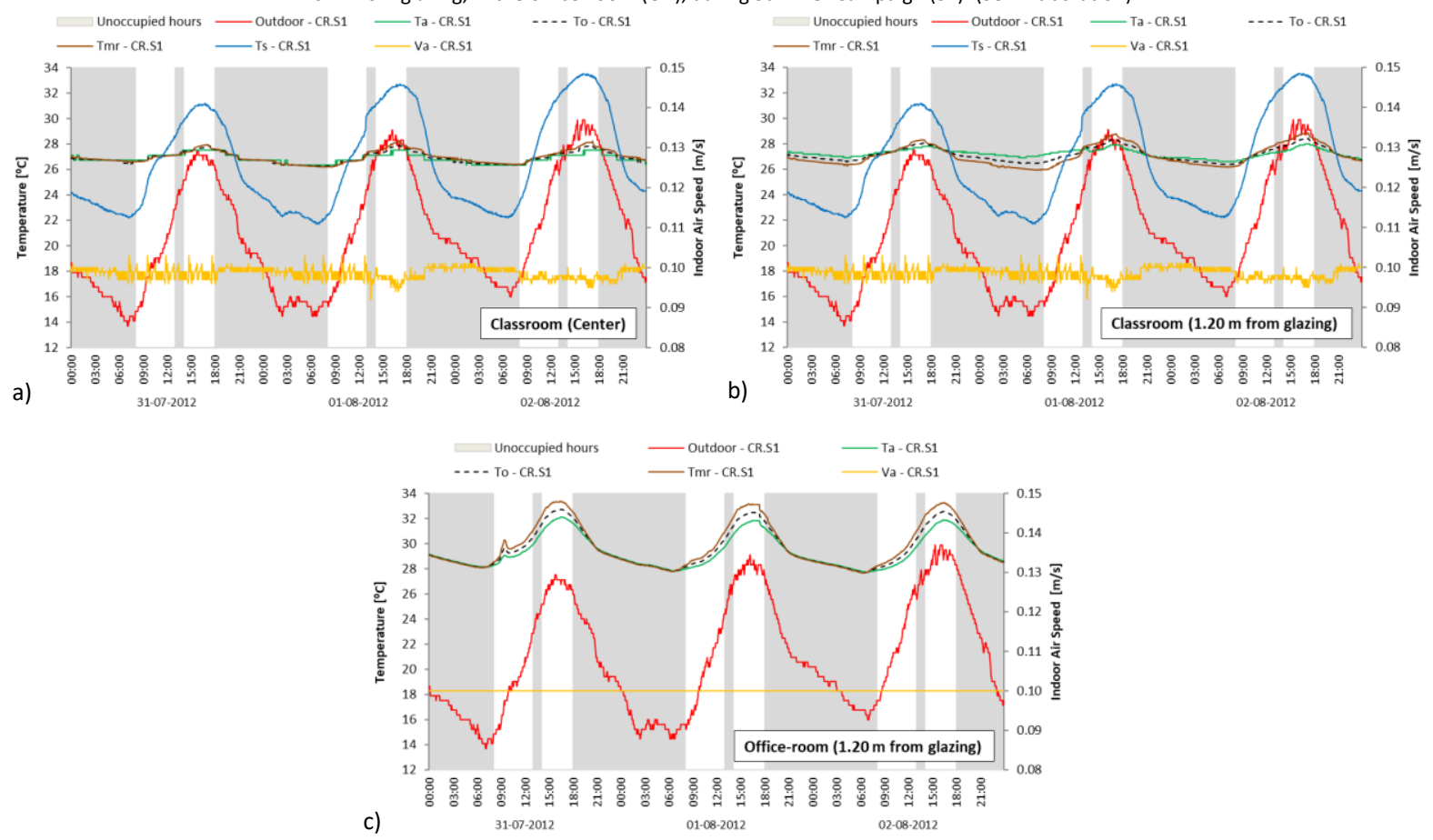

In the winter campaign, it was not possible to measure the globe temperature in the classroom, nor the parameters that would allow the calculation of Tmr. Thus, the results presented below for these periods relate only to the officeroom.

Figure 10. Mean Radiant Temperature and Operative Temperature, calculated for the center and at $1.20 \mathrm{~m}$ from the glazing, in the office-room (OR), during winter Campaign (W1): a) Clear sky; b) Overcast sky. (Self-Elaboration).
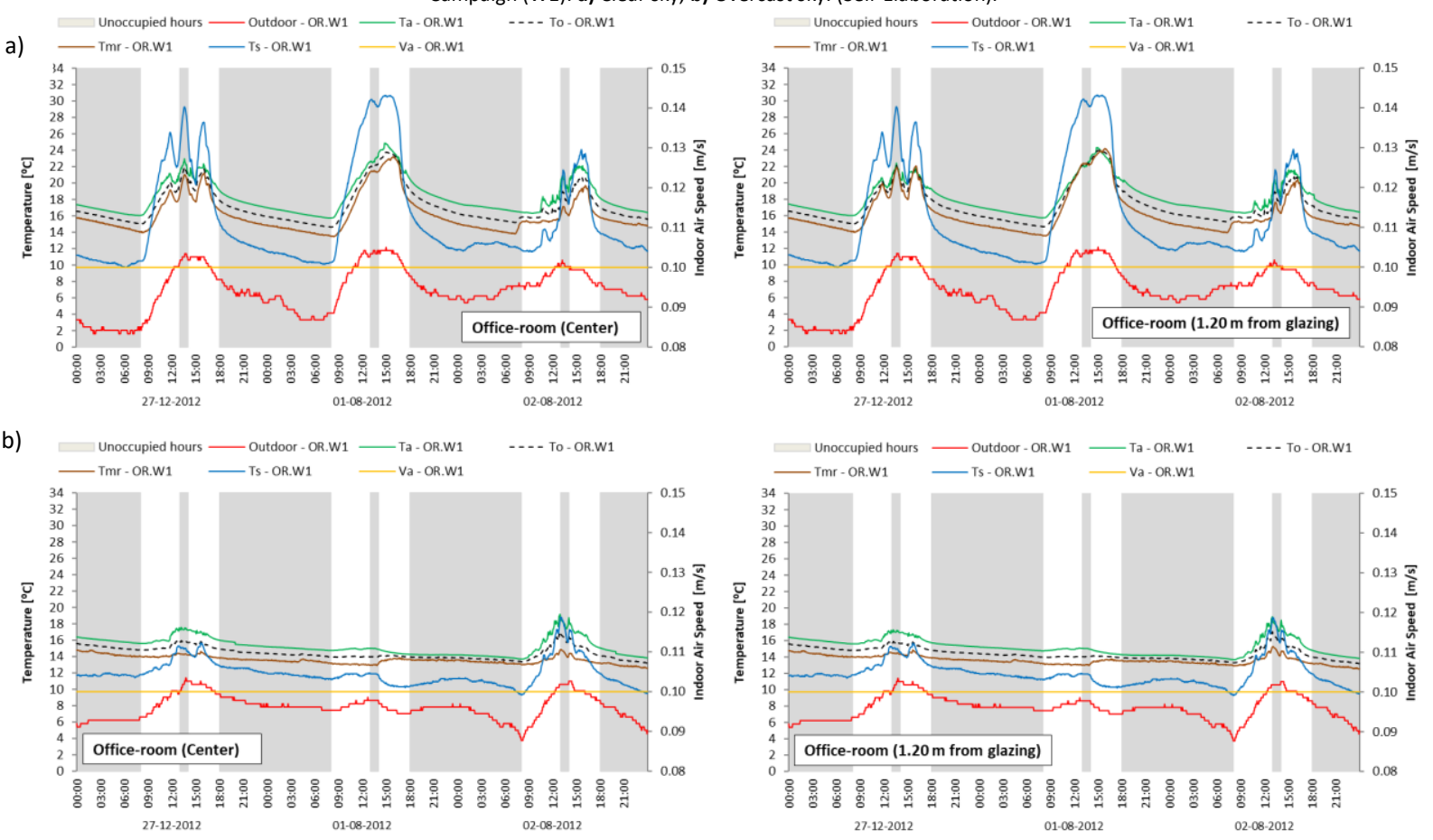

To complement this evaluation, a statistical analysis of the results obtained in the classroom and in the office-room is presented in Table 6. 
Table 6. Statistical analysis of the registered and calculated values during the first periods of summer and winter campaigns (a). (Self-Elaboration).

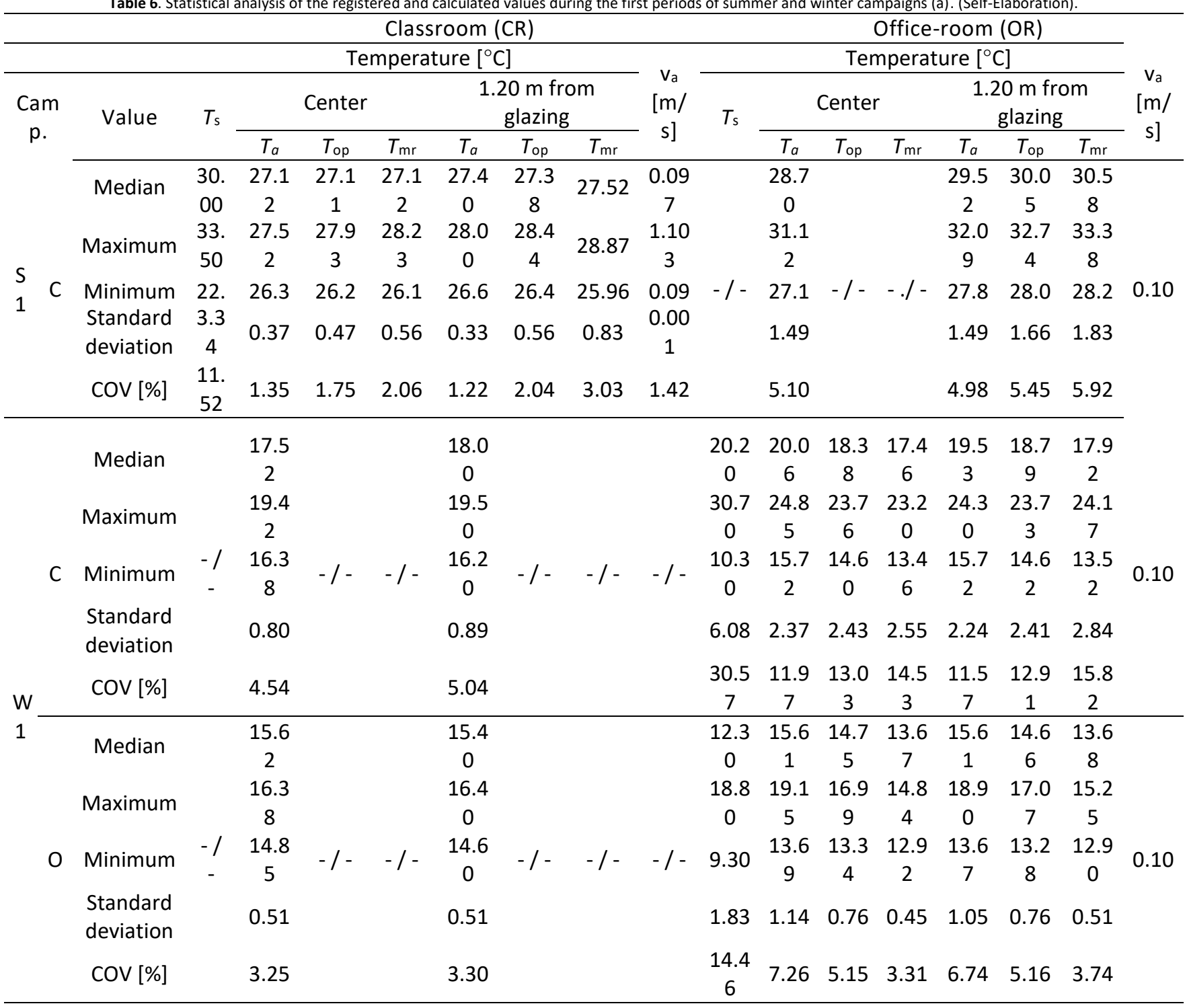

C - Clear sky; O - Overcast sky; COV - Coefficient of Variation; (a) Considering only the hours of possible occupation (normal schedule: from 8:00 am to 1:00 pm and from 2:00 pm to 6:00 pm, on week days; from 8:00 am to 1:00 pm, on Saturdays).

The values of the Operative Temperature, at the center of the spaces and at $1.20 \mathrm{~m}$ from the glazing, present a strong correlation with the recorded values of the indoor air temperature. It should be noted that the values of the Operative Temperature are influenced by the temperature of the surfaces that surround the space and, specifically, by the surface temperature of the glazing. For air speed values less than $0.20 \mathrm{~m} / \mathrm{s}$, as in the studied indoor spaces, air speed does not have a significant effect on the Operative Temperature value. For the situations where measured values were missing, approximate values of operative temperature were calculated with the correlation formulae between the Operative Temperature and the Indoor Air Temperature and were used for comfort models application presented ahead (graphic method and adaptive models).

\section{PMV and PPD indices}

The on site evaluation of thermal comfort involves the measurement of the environmental and individual parameters necessary for the calculation of comfort indices PMV and PPD referred to in section 2.2. The registration of environmental parameters was continuous. For the individual parameters, a standing person with a metabolic rate of 1.2 met and clothing of 1.0 clo was considered, in winter Campaign and 1.2 met and 0.5 clo, in Summer Campaign. The calculation of PMV and PPD was carried out according to the formulae provided by EN ISO 7730 (2005). For Summer Campaign, figure 11, the application of PMV and PPD indices, for possible occupation hours, shows that the office-room does not guarantee its users the minimum conditions of comfort. In the office-room, in areas near the glazing, $100 \%$ of 
the measured values are outside the comfort zone, not complying with any of the acceptable thermal environment categories, with a PMV varying between +0.99 and +2.41 .

In the classroom, the discomfort is much lower but it worsens in the areas near the glazing, 56.96\% in the center and $70.70 \%$ at $1.20 \mathrm{~m}$ from glazing of values out of comfort conditions. In the classroom, especially in the center, a significant part of the measured values, $43.04 \%$, is inside the comfort zone, corresponding to category C (PPD $<15 \%$ and $-0,7<$ PMV $<+0,7)$ defined in EN ISO 7730 (2005). In each graph of figure 11, percentages of hours complying with the conditions of thermal environment categories (A, B and C) and the percentage of those out of any category (OUT) are presented in a box, considering only possible occupation hours.

Figure 11. PMV and PPD Indices, during Summer Campaign (S1), during possible occupation hours: a) In the classroom (CR); b) In the office-room (OR). (Self-Elaboration).
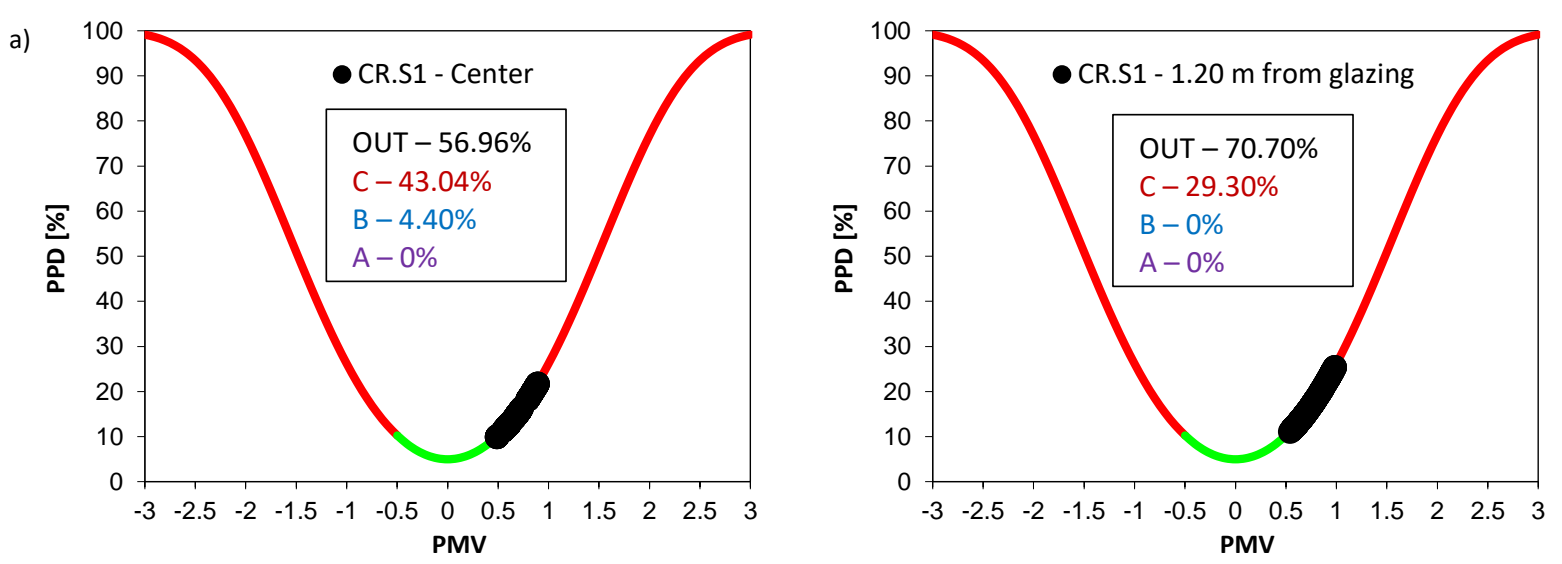

b)

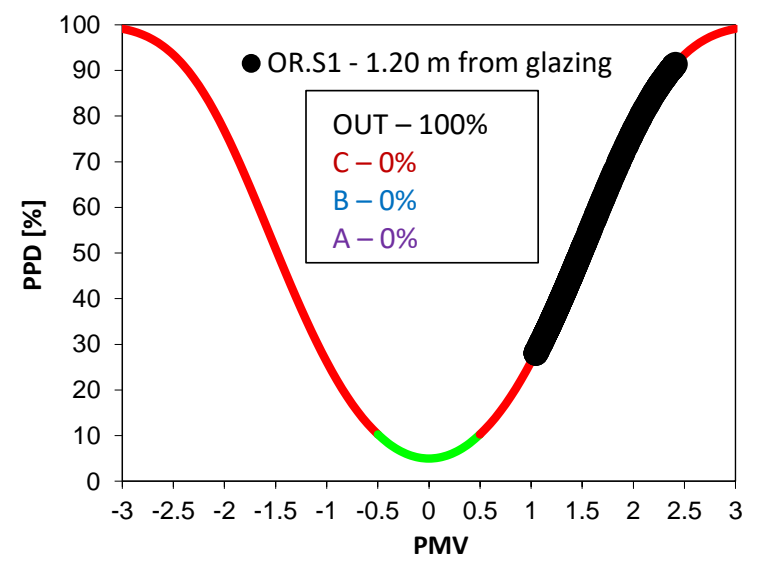

In winter Campaign, Figure 12, the indices show office-room users are comfortable in a low percentage of time on clear days $(16.80 \%$ of the values in the center and $16.67 \%$ at $1.20 \mathrm{~m}$ from the glazing), meeting acceptable thermal comfort conditions, corresponding to category $\mathrm{B}$ (PPD $<10 \%$ and $-0,5<\mathrm{PMV}<+0,5$ ). On the days with overcast sky, there is always discomfort, from slightly cold to cold, with PMV varying between -0.98 and -1.73 in the center and at $1.20 \mathrm{~m}$ from the glazing, varying between -0.95 and -1.74 . In each graph of figure 12 , percentages of hours complying with the conditions of thermal environment categories ( $\mathrm{A}, \mathrm{B}$ and $\mathrm{C}$ ) and the percentage of those out of any category (OUT) are presented in a box, considering only possible occupation hours.

Figure 12. PMV and PPD indices, during winter Campaign (W1), in the office-room (OR), at the center and at $1.20 \mathrm{~m}$ from the glazing, during possible occupation hours: a) Clear sky; b) Overcast sky. (Self-Elaboration).
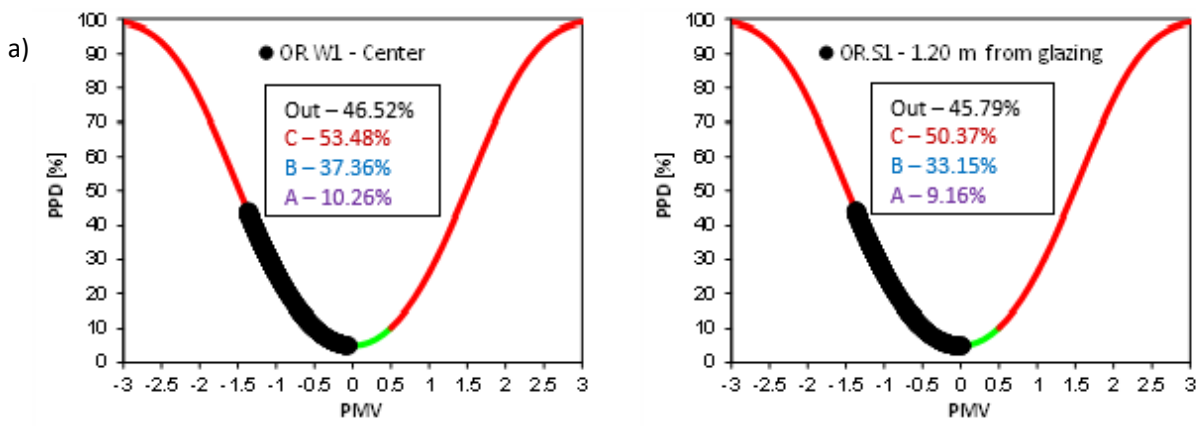
b)

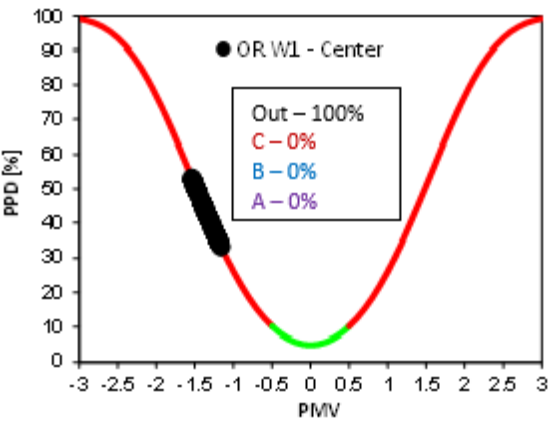

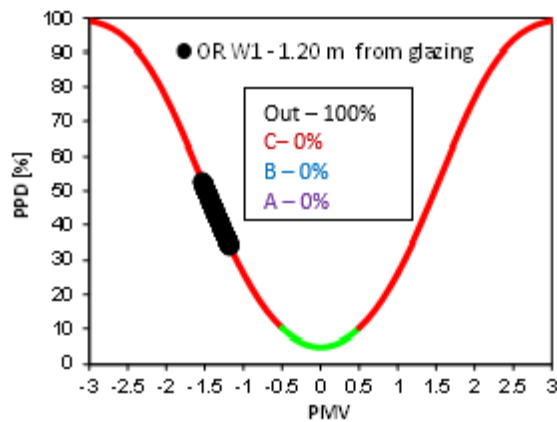

To complement this evaluation, the statistical analysis of the results is presented in Table 7.

Table 7. Statistical analysis of PMV and PPD indices, registered in the first periods of summer and winter campaigns (a). (Self-Elaboration).

\begin{tabular}{|c|c|c|c|c|c|c|c|c|c|c|}
\hline & & & & Clas & room (CR & & & Offic & e-room ( & \\
\hline & & & & iter & $1.20 \mathrm{~m} \mathrm{f}$ & $\mathrm{n}$ glazing & & iter & $1.20 \mathrm{~m}$ & n glazing \\
\hline Camp & $\operatorname{lgn}$ & value & PMV & PPD [\%] & PMV & PPD [\%] & PMV & PPD [\%] & PMV & PPD [\%] \\
\hline & & Median & 0.71 & 15.59 & 0.78 & 17.77 & & & 1.59 & 55.64 \\
\hline & & Maximum & 0.92 & 23.06 & 1.07 & 29.36 & & & 2.41 & 91.38 \\
\hline & & Minimum & 0.46 & 9.40 & 0.50 & 10.31 & & & 0.99 & 25.73 \\
\hline S1 & C & Standard & 0.13 & 3.80 & 0.16 & 5.39 & $-/-$ & $-/-$ & 0.49 & 23.76 \\
\hline & & $\begin{array}{l}\text { Coefficient of } \\
\text { Variation [\%] }\end{array}$ & 17.79 & 23.76 & 19.91 & 28.43 & & & 28.62 & 39.11 \\
\hline & & Median & & & & & -0.63 & 13.33 & -0.63 & 13.28 \\
\hline & & Maximum & & & & & 0.30 & 48.14 & 0.41 & 47.83 \\
\hline & & Minimum & & & & & -1.45 & 5.00 & -1.44 & 5.00 \\
\hline & C & $\begin{array}{l}\text { Standard } \\
\text { deviation }\end{array}$ & $-/-$ & $-/-$ & $-/-$ & $-/-$ & 0.46 & 12.50 & 0.49 & 12.87 \\
\hline W/1 & & $\begin{array}{l}\text { Coefficient of } \\
\text { Variation [\%] }\end{array}$ & & & & & 69.81 & 63.19 & 75.23 & 67.77 \\
\hline$V V 1$ & & Median & & & & & -1.42 & 46.49 & -1.43 & 46.95 \\
\hline & & Maximum & & & & & -0.98 & 63.54 & -0.95 & 64.04 \\
\hline & & Minimum & & & & & -1.73 & 25.30 & -1.74 & 24.13 \\
\hline & 0 & $\begin{array}{l}\text { Standard } \\
\text { deviation }\end{array}$ & $-1-$ & $-1-$ & $-1-$ & $-/-$ & 0.16 & 8.55 & 0.16 & 8.48 \\
\hline & & $\begin{array}{l}\text { Coefficient of } \\
\text { Variation [\%] }\end{array}$ & & & & & 11.32 & 18.01 & 11.16 & 17.73 \\
\hline
\end{tabular}

C - Clear sky; O - Overcast sky; (a) Considering only the hours of possible occupation (normal schedule: from 8:00 am to 1:00 pm and from 2:00 pm to 6:00 pm, on week days; from 8:00 am to 1:00 pm, on Saturdays).

\section{Graphic comfort zone method}

In order to verify if the application of the Graphic Comfort Zone method proposed by ANSI/ASHRAE 55 (2010) can be used instead of the PMV and PPD indices and obtain equivalent results, using only the measurements of temperature and humidity values, the Graphic Comfort Zone method was applied. Such methodology uses the Operative Temperature as indoor reference temperature and requires the determination of the absolute humidity of the air from the measurements of indoor air temperature and relative humidity. As said before, when, in the classroom, during some of the periods under analysis, measurements were not possible that would allow the calculation of the Operative Temperature, in the application of thermal comfort assessment models presented below, approximate values of Operative Temperature were calculated, from the correlation formulae between the Operative Temperature and the Indoor Air Temperature.

During Summer Campaign, Figure 13, in the classroom (CR), 40.50\% of the values of Operative Temperature in the center are within the comfort zone (IN), while in the area next to the glazing only $27.50 \%$ of the values fall into the comfort zone. In the office-room (OR), in the center, $96.70 \%$ of the measured values are out of comfort (OUT) and this discomfort is more pronounced in areas near the glazing, where all the measured values are outside the comfort zone. 
Figure 13. Application of the graphic comfort zone method during Summer Campaign (S1), during possible occupation hours, a) at the center (left) and b) at $1.20 \mathrm{~m}$ from the glazing (right). (Self-Elaboration).
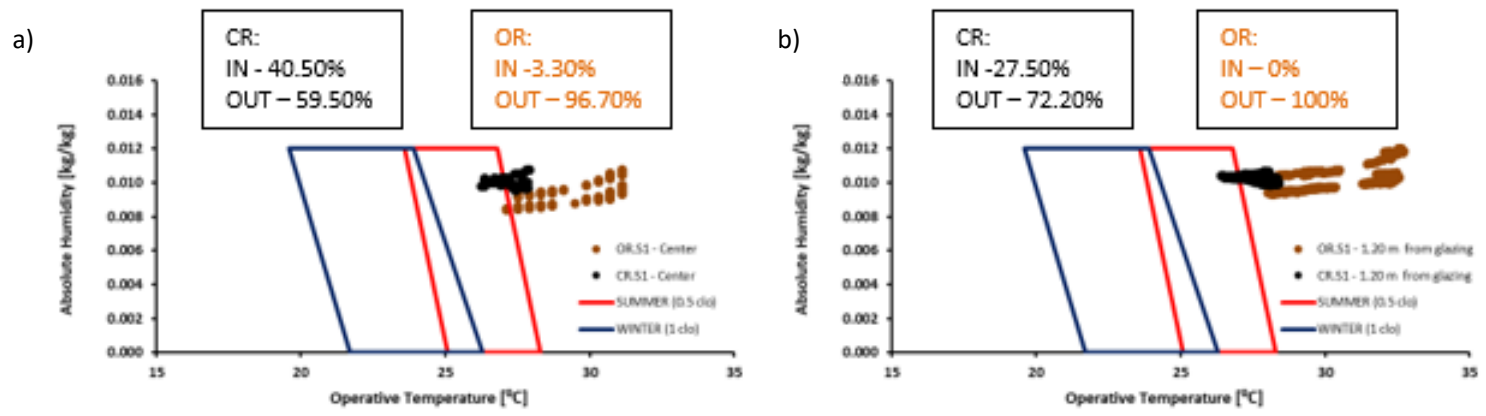

During winter Campaign, Figure 14, with heating system OFF, for clear sky, in the center and in the vicinity of the classroom windows, all values are outside the comfort zone due to the sensation of cold. In the office-room, both in the center and in the areas near the glazing, there are values within the comfort zone on days with clear sky, corresponding to $8.30 \%$ in the center and $8.60 \%$ at $1.20 \mathrm{~m}$ from the glazing. On overcast days, in the classroom and in the office-room, all measured values are outside the comfort zone due to excess cold.

Figure 14. Application of the graphic comfort zone method during winter Campaign (W1), during possible occupation hours, at the center (left) and at $1.20 \mathrm{~m}$ from the glazing (right): a) Clear sky; b) Overcast sky. (Self-Elaboration).
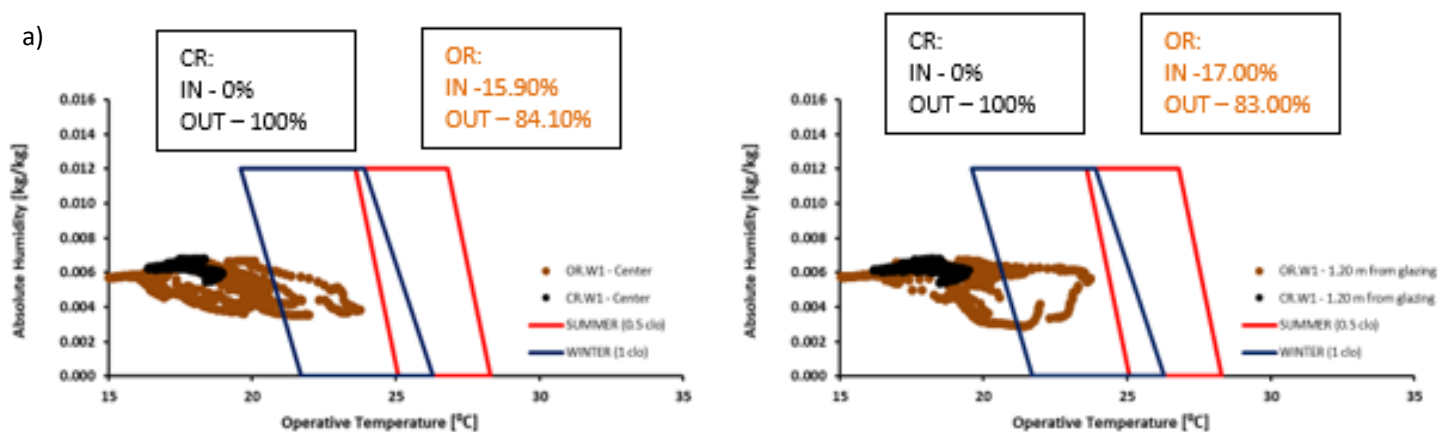

b)
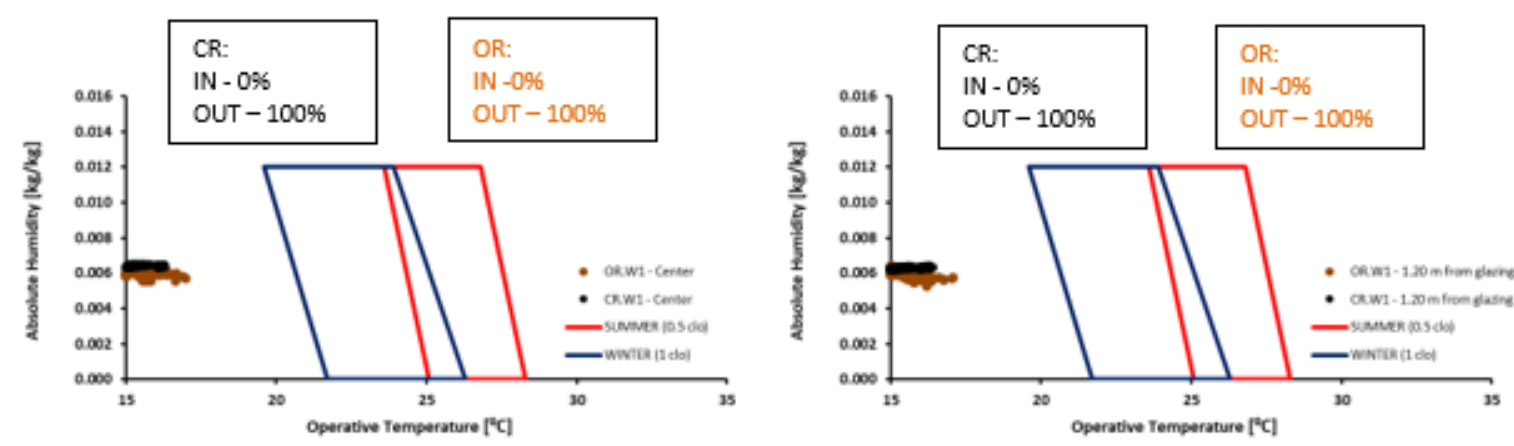

\section{Adaptive models}

Taking into account the outdoor air temperatures registered in the measurement campaigns, in this study the ASHRAE 55 method was not applied in winter period W1, since it does not apply when the mean outdoor air temperature is below $10^{\circ} \mathrm{C}$ and a great part of the recorded values for that period were below $10^{\circ} \mathrm{C}$. The EN 15251 and LNEC models could be applied in both seasons. It must be reminded that category IV defined in EN 15251 corresponds to all the situations that do not comply with the first three categories and therefore are considered of thermal discomfort. In the Summer Campaign, Figure 15, the application of the various models in the classroom (CR) shows that most of the results lie within the zone of thermal comfort, $69.00 \%$ in the center and $54.80 \%$ at $1.20 \mathrm{~m}$ from the glazing, with $80 \%$ of acceptability, according to ANSI/ASHRAE 55 (2010) method.

According to EN 15251 (2007) method, all of the results lie within the zone of thermal comfort, both in the center and at $1.20 \mathrm{~m}$ of the glazed window (category II and III). In the application of LNEC (Matias, 2010) model, $73.10 \%$ of the 
recorded values at the center of the classroom is within the comfort zone (within the comfort limits for when the system is OFF, identified as "OFF" in the graphs captions) and $54.20 \%$ of them, at $1.20 \mathrm{~m}$ from the glazing. In the office-room $(\mathrm{OR})$, the temperature values have a more pronounced variation. At $1.20 \mathrm{~m}$ from the glazing, all the values are outside the comfort zone (OUT) and only $19.20 \%$ of the results lie within thermal comfort zone in the center, for ANSI/ASHRAE 55 (2010) method. According to EN 15251 (2007) method, $56.60 \%$ of the results in the center and $45.40 \%$ at $1.20 \mathrm{~m}$ from the glazing are at least complying with category III conditions.

For LNEC (Matias, 2010) model, all the values are outside the comfort zone (OUT) near the glazing and only $15.00 \%$ of the results lie within thermal comfort zone in the center (OFF). In general, the various adaptive models identified the same tendencies regarding thermal comfort conditions in the rooms under analysis. However, it should be noted that the EN 15251 (2007) model is by far the least demanding in what concerns the excess heat discomfort.

Figure 15. Assessment of thermal comfort through the application of adaptive models, during Summer Campaign (S1): a) ASHRAE Model; b) EN 15251 (2007) Model; c) LNEC (Matias, 2010) Model. (Self-Elaboration).

a)
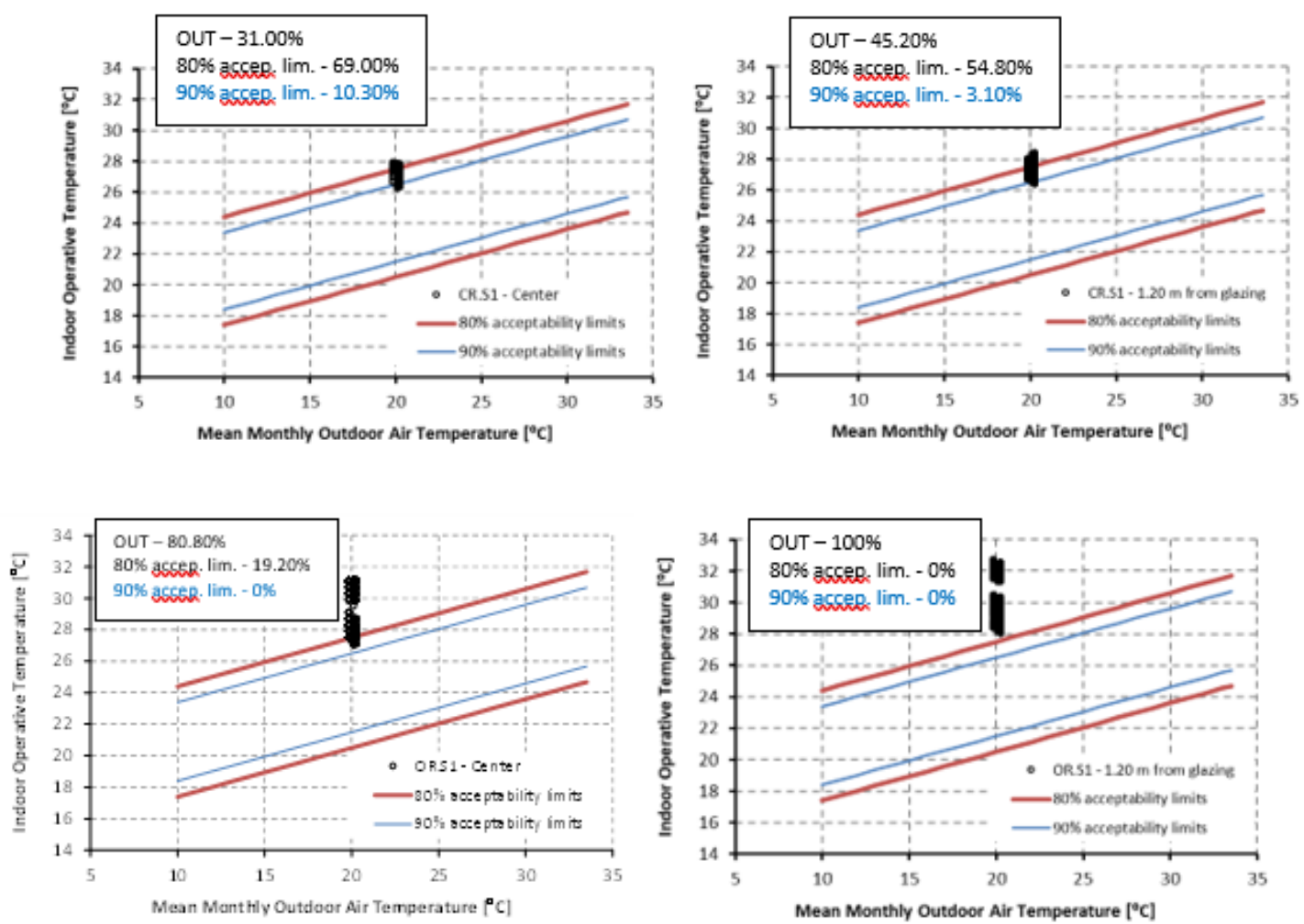

b)
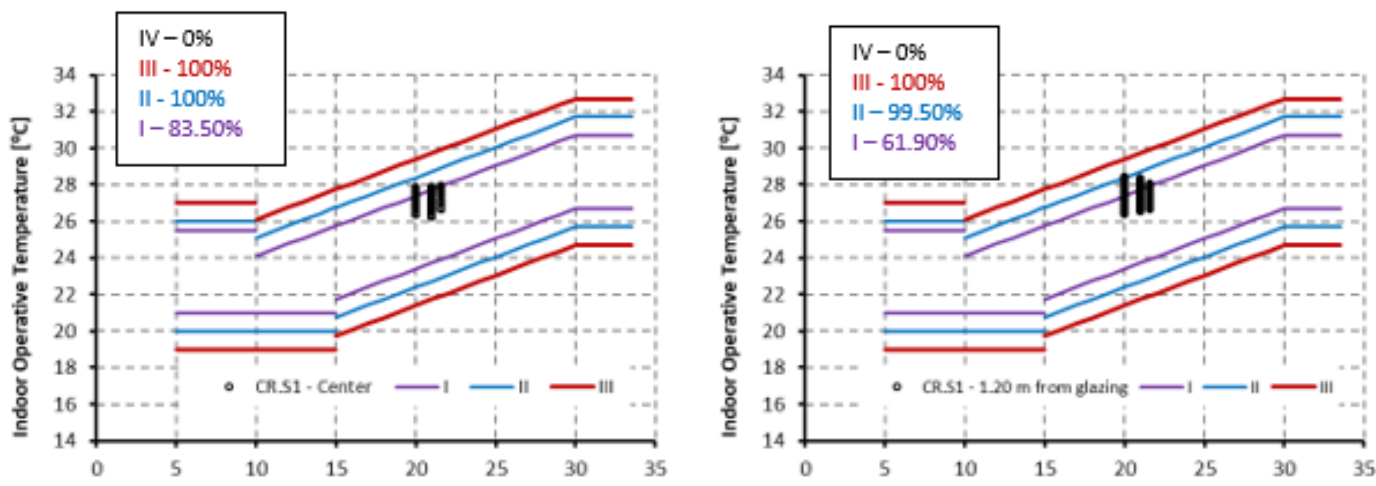

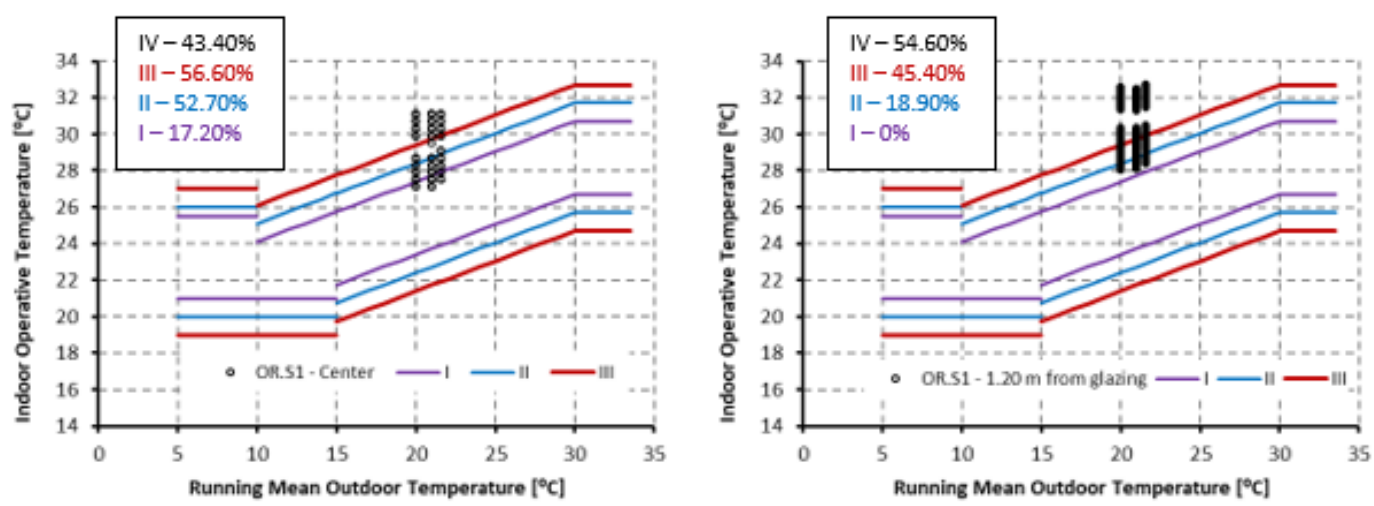

c)
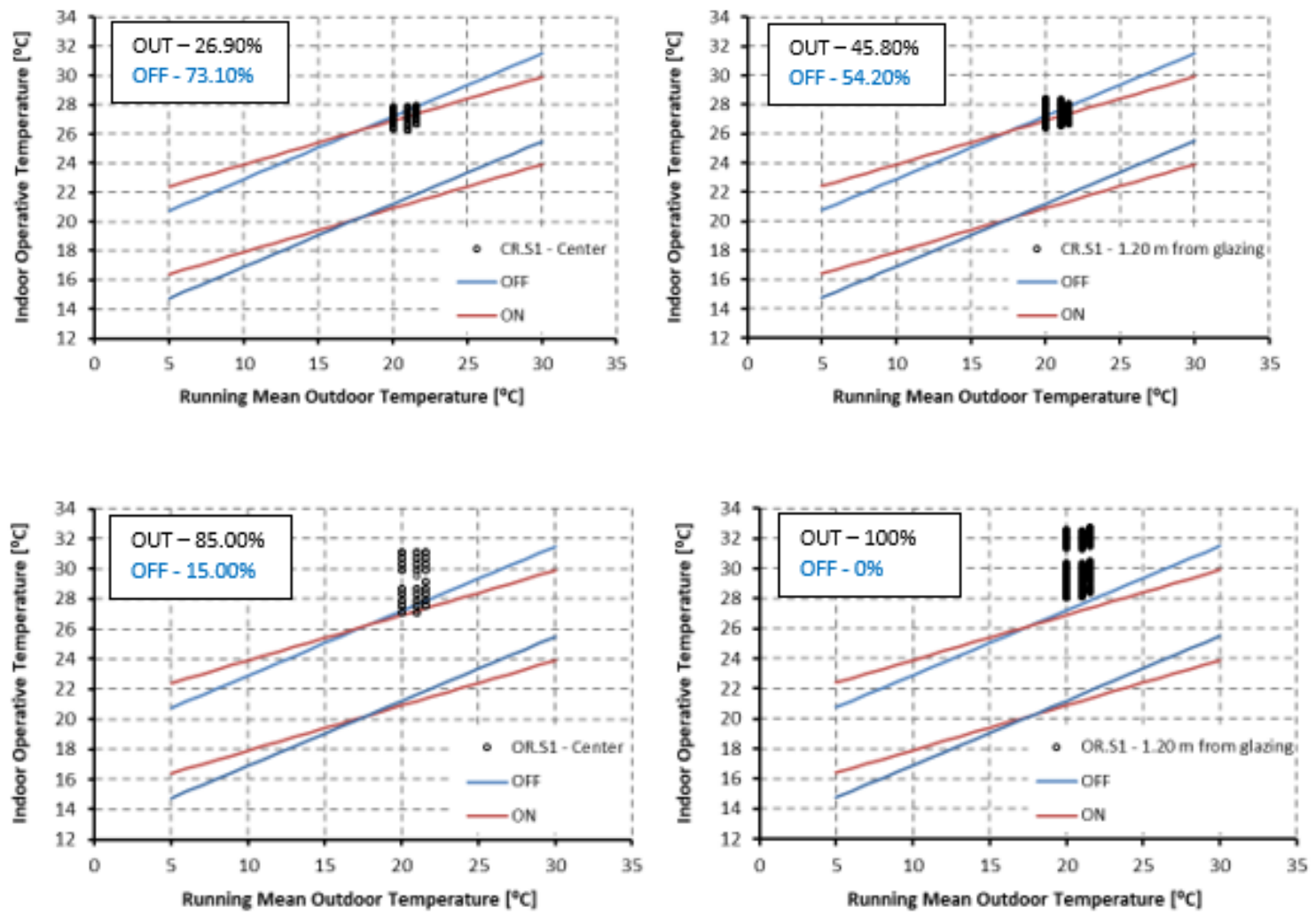

Regarding the winter campaign, Figure 16, in the classroom (CR), for clear sky, only $10.4 \%$ of the operative temperature values in the center lie within the thermal comfort zone, category III of the model of EN 15251 (2007) and $8.80 \%$ near the glazing. For overcast sky, there are no comfortable hours in the classroom for this model. According to LNEC (Matias, 2010) model, for clear sky, more than $82 \%$ of the results are considered comfortable, even in the zones near the glazing. On overcast days, LNEC (Matias, 2010) model considers more than $33 \%$ of the results comfortable.

In the office-room (OR), for clear sky, the values are more dispersed, both in the center and in the areas near the glazing. For EN 15251 (2007) model, for the center and for the zone near the glazing, $46.90 \%$ and $46.20 \%$ of the results, respectively, fall at least in category III. For overcast sky, there are no comfortable hours in the office-room, for this model. In the application of LNEC (Matias, 2010) model, for clear sky, $60.30 \%$ of the results are within the comfort zone and, besides the values outside this zone due to a sensation of cold (OUT), $10.60 \%$ of the values in the center and $11.20 \%$ near the glazing are out of the comfort zone but due to a sensation of warmth (OUT for excessive warmth, in the captions). For overcast sky, in the office-room, $9.90 \%$ and $8.20 \%$ of the results are considered comfortable, in the center and at $1.20 \mathrm{~m}$ from the glazing, respectively. 
Figure 16. Assessment of thermal comfort through the application of adaptive models, during winter Campaign (W1), for clear and overcast sky: a) EN 15251 (2007) Model; b) LNEC (Matias, 2010) Model. (Self-Elaboration).

a)
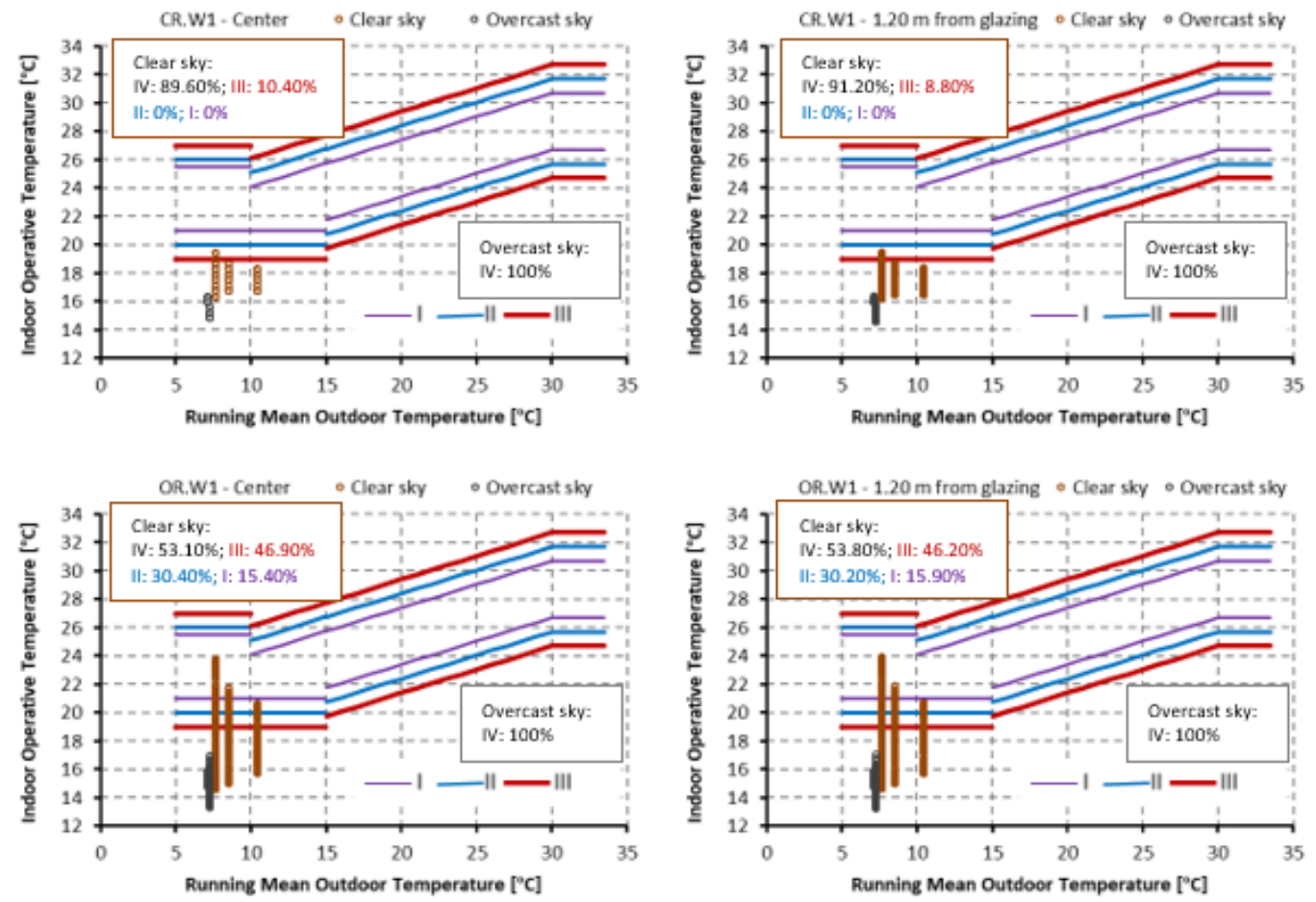

b)
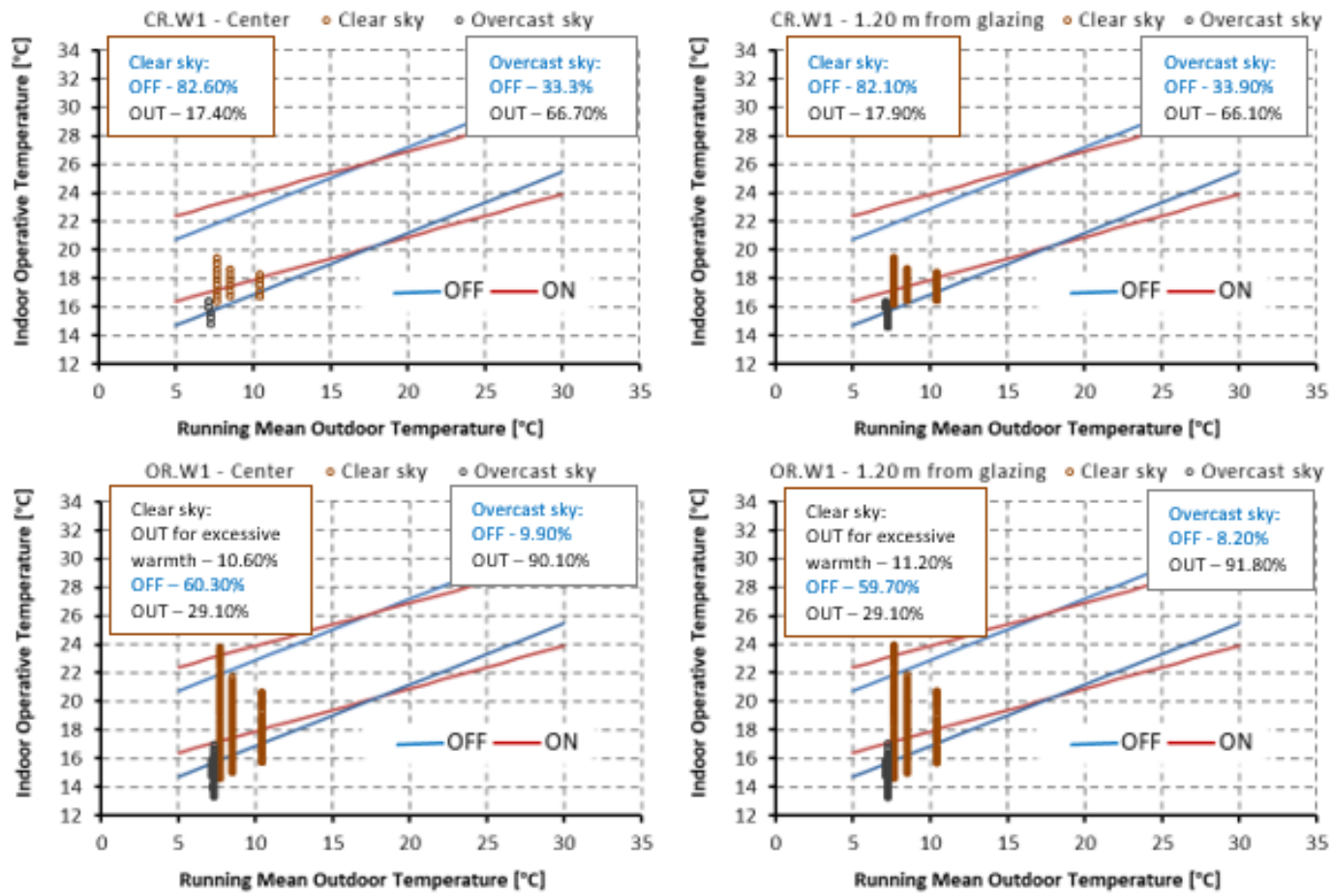

We can also observe the different options for calculations, the outdoor reference temperature, in the models of ANSI/ASHRAE 55 (2010), is the monthly mean outdoor air temperature and in the EN 15251 (2007) and the Model Proposed by LNEC (Matias, 2010) is calculated with the daily mean outdoor air temperature of the previous seven days, according to equation (2).

\section{Discussion and conclusions}

The reported results showed that there is a significant difference in comfort conditions between the center of the rooms and the vicinity of glazed façades, depending on the exposure of the glazing to solar radiation, the geometry of the 
space and the ratio between the glazing area and the floor area. Differences between $0.5{ }^{\circ} \mathrm{C}$ and $2.5^{\circ} \mathrm{C}$ were found. In summer, temperatures turned out to be much more variable in the office-room than in the classroom, where there is some shading of the window. In summer, the office-room window is very much exposed to the sun, making the indoor air temperature reach a maximum of $32.09{ }^{\circ} \mathrm{C}$ at $1.20 \mathrm{~m}$ from the glazing, which is $4{ }^{\circ} \mathrm{C}$ more than the maximum temperature reached in the classroom. In the same location, Mean Radiant Temperature reached a maximum of 33.38 oC. The median temperature is also around $2{ }^{\circ} \mathrm{C}$ higher than in the classroom.

In winter, on clear sky days, the sun reaches both spaces in an identical way. However, given the geometric characteristics of the office-room (smaller volume and much greater glazing to floor area ratio than in the classroom), maximum temperatures in the office-room are up to $5{ }^{\circ} \mathrm{C}$ higher than those reached in the classroom. On the other hand, the minimum temperatures are generally lower in the office, thus confirming the greater variability of its temperature. As for the application of comfort assessment models, all of them proved to be sensitive to the difference between the center of the rooms and the vicinity of the glazing surfaces. This sensitivity is more evident in summer. The most tolerant model for summer is the EN 15251 model accepting as 100\% comfortable situations that, for other methods such as PMV/PPD and the graphic method, do not reach comfort in more than $50 \%$ of the time.

LNEC model leads to results very similar to that of ANSI/ASHRAE, in summer. Both models consider, for the classroom, a percentage of the comfort hours that goes from about $54 \%$ close to the glazing to about $70 \%$ in the center of the space. In the office-room, the percentages indicated by the two methods are also identical, being $0 \%$ next to the glazing. In winter, LNEC method leads to percentages of comfort hours clearly higher than any other method. For example, in the most pronounced situation (classroom, open sky), there is a difference of $82 \%$ between the results of LNEC model and the ones of graphical method. It is evident that LNEC model clearly reflects the habits of the Portuguese who do not usually use continuous space heating and who are used, therefore, to feeling comfortable in relatively low temperatures.

Some conclusions may be drawn from the results of the present study. For each of the main objectives, the following points are highlighted:

1) To evaluate thermal comfort conditions at the center of the spaces and in the areas near the glazing:

- There was clearly a greater variability of comfort conditions in the vicinity of the glazed walls when compared to the center of the rooms;

- In general, the proximity of the glazing contributes to the user's greater discomfort, both in terms of excess heat and in terms of excess cold. This is mainly due to heat exchanges by radiation with the surface of the glazing and to the direct incidence of solar radiation on occupants, when shading and protection devices are not used.

2) To evaluate the applicability of thermal comfort assessment models:

- The thermal comfort assessment models applied are, indirectly, sensitive to the variability of the existing conditions and factors of local discomfort. Thus its application is more fallible in more critical places, such as in the vicinity of glazing than in the center of the room where, depending on its geometry and thermal inertia, the hygrothermal parameters are more stable;

- However, the application of thermal comfort assessment models to the two studied rooms was able to reveal the differences between the two compared locations within each space and, despite some differences in the assessment of the results, the conclusions to be drawn from the application of the different models do not differ much between them;

- $\quad$ The PMV and PPD indices allowed evaluating the comfort conditions both in the center of the spaces and in the areas near the glazing, being sensitive to the variation of the Mean Radiant Temperature and of the air temperature in each location. On the other hand, the seven-level scale allows a more objective quantitative classification of the comfort conditions of the areas under study;

- In relation to the application of the Graphic Comfort Zone Method, in global terms, the conclusions to be drawn do not deviate much from those obtained through the PMV and PPD indices;

- When comparing the results obtained by the different models, the fact that the adaptive models allow a greater tolerance to the discomfort felt by the users must be highlighted. Considering the local climate and the possibility of users adaptation, these models reflect more accurately the actual comfort conditions for the users. The adaptive models provide a method to assess long term comfort, in order to provide an overall number which is indicative of the space performance over a longer period (not just one point in time evaluation). Adopting this will provide a method to interpret the results in a better way (more than only min, max, average and standard deviation measurements). Thus, among the tested models, LNEC (Matias, 2010) model is the most recommended for Portuguese buildings, since its design 
took into account the Portuguese climate and habits and was based on the results obtained in an extensive set of surveys of indoor environment conditions, carried out in Portuguese residential and nonresidential buildings, and on the thermal perception expressed by the respective users;

- It is also concluded that, in order to characterize the indoor thermal comfort through the application of comfort models, at the center of the spaces, it is not necessary to use very complex and sophisticated measuring equipment (microclimatic stations). Temperature, relative humidity and air speed sensors proved to be sufficient.

3) To evaluate the effect of incoming solar radiation at indoor spaces:

- By the analysis of summer campaign, it becomes very clear that the use of solar protection devices, for this orientation of windows, is extremely important, since it is proved that without that protection there are no conditions for thermal comfort indoors;

- During winter campaign, in the overcast days, the results are very similar at the center and at $1.20 \mathrm{~m}$ from glazing. When there is solar radiation (clear sky) comfort conditions improve in a very significant way;

- As expected, it was found that the incidence of solar radiation inside the spaces is negative on hot days, in summer, but during the rest of the year (with the possible exception of early autumn and late spring) it may be positive, ensuring by itself a few hours of thermal comfort inside unheated spaces, even during the winter. However a great variation and even a few hours of overheating may occur, pointing out that these solar gains must be carefully managed.

4) To evaluate the effect of the geometry of the spaces and of the ratio between glazed area and floor area:

- Comparing the results for the classroom, with greater depth and, consequently, more absorbent surface (greater thermal inertia) and for the office-room in which the largest dimension corresponds to the wall of the façade and its depth is reduced, it can be seen that there is a much higher temperature stability in the classroom, especially in the center;

- Another important aspect is the ratio between the glazing area and the floor area. In the office-room, where the glazed area corresponds to $35 \%$ of the floor area, the influence of glazing is much greater than in the classroom, where the area of glazing exposed to the Sun is only $11 \%$ of the floor area.

The results presented in this paper relate to measurements periods where the existing indoor venetian blinds, purposely, were not used, in order to assess the effect of maximum solar exposure. However, it should be noted that in the classroom there is a horizontal overhang with a depth of $1.00 \mathrm{~m}$ above the $\mathrm{SW}$-oriented window, while in the officeroom there is no obstacle shading its window, which is also SW-oriented. Thus, in addition, it was possible to evaluate the effect of the horizontal shading overhang above the classroom window. For the classroom, during summer campaign, since the trajectory of the Sun is high the overhang protects the glazing in the hours of the greatest solar intensity and the results obtained in the center and at $1.20 \mathrm{~m}$ from the glazing were very similar. On the contrary, in the office-room, with no shading device, the values recorded at $1.20 \mathrm{~m}$ from the glazing are much higher than those recorded in the classroom and all those values are outside the comfort zone.

\section{References}

ANSI/ASHRAE 55 (2010). Thermal Environmental Conditions for Human Occupancy. American Society of Heating, Refrigeration and Air-Conditioning Engineers. [American National Standard]. Atlanta.

Arens, E., Hoyt, T., Zhou, X., Huang, L., Zhang, H., \& Schiavon, S. (2015). Modeling the comfort effects of short-wave solar radiation indoors. Building and Environment, 88, 3-9. https://doi.org/10.1016/j.buildenv.2014.09.004

Augusto, L. D., Giacomet, B., \& Mendes, N. (2007). Numerical Method for Calculating View Factor Between Two Surfaces. Proceedings: Building Simulation 2007, 269-274. http://www.ibpsa.org/proceedings/BS2007/p757_final.pdf

Bessoudo, M., Tzempelikos, A., Athienitis, A., \& Zmeureanu, R. (2007). Simulation of Thermal Comfort Conditions in Highly Glazed Perimeter Zones with Shading Devices. 2nd Canadian Solar Buildings Conference, Concordia University, Calgary, Canada, June 10-14, 2007.

Bessoudo, M., Tzempelikos, A., Athienitis, A., \& Zmeureanu, R. (2010). Indoor Thermal Environmental Conditions Near Glazed Façades with Shading Devices - Part I: Experiments and Building Thermal Model. Building and environment, 45, 2506-1506. https://doi.org/10.1016/j.buildenv.2010.05.013

Carlucci, S., Bai, L., de Dear, R., \& Yang, L. (2018). Review of adaptive thermal comfort models in built environmental regulatory documents. Building and Environment, 137, 73-89. https://doi.org/10.1016/j.buildenv.2018.03.053

de Dear, R., Brager, G., \& Cooper, D. (1997). Developing an Adaptive Model of Thermal Comfort and Preference. Final Report, American Society of Heating, Refrigeration and Air-Conditioning Engineers, ASHRAE RP-884. 
DGEG/ADENE (Direção Geral de Energia e Geologia/ Agência para a Energia). (2020). Energia em Números. Direção de Serviços de Planeamento Energético e Estatística da DGEG e Agência para a Energia, Unidade de Informação, Lisbon. https://www.dgeg.gov.pt/media/43zf5nvd/energiaem-números-edição-2020.pdf

EN ISO 7726. (2001). Ergonomics of the Thermal Environment. Instruments for Measuring Physical Quantities. CEN (European Committee for Standardization). Geneva.

EN ISO 7730. (2005). Ergonomics of the Thermal Environment. Analytical Determination and Interpretation of Thermal Comfort Using Calculation of the PMV and PPD Indices and Local Thermal Comfort Criteria. CEN (European Committee for Standardization). Geneva.

EN 15251. (2007). Indoor Environmental Input Parameters for Design and Assessment of Energy Performance of Buildings. Addressing Indoor Air Quality, Thermal Environment, Lighting and Acoustic. CEN (European Committee for Standardization). Geneva.

Fanger, P. O. (1970). Thermal comfort: Analysis and Applications in Environmental Engineering. Danish Technical Press.

Huizenga, C., Zhang, H., Mattelaer, P., Yu, T., Arens, E., \& Lyons, P. (2006). Windows Performance for Human Comfort - Final Report to National Fenestration Rating Council. Center for the Built Environment, University of California, Berkeley, United States. Available on: http://www.healthyheating.com/HH_Integrated_Design/Week1/WINDOWPERFORMANCEFORThermalcomfort.pdf

La Gennusa, M., Nucara, A., Pietrafesa, M., \& Rizzo, G. (2007). A Model for Managing and Evaluating Solar Radiation for Indoor Thermal Comfort. Solar Energy, 81, 594-606. https://doi.org/10.1016/j.solener.2006.09.005

La Gennusa, M., Nucara, A., Rizzo, G., \& Scaccianoce, G. (2005). The Calculation of the Mean Radiant Temperature of a Subject Exposed to the Solar Radiation - A Generalised Algorithm. Building and Environment, 40, 367-375. https://doi.org/10.1016/j.buildenv.2004.06.019

Matias, L. M. (2010). Desenvolvimento de um Modelo Adaptativo para Definição das Condições de Conforto Térmico em Portugal. Coleção Teses e Programas de Investigação do LNEC (TPI), TPI 65, Lisbon.

Matias, L. M, \& Pina dos Santos, C. (2013). Adaptive thermal comfort in the residential setor in Portugal. Congesso Internacional da Habitação no Espaço Lusófono. 20 CIHEL, LNEC, Lisbon, 13 - 15 March, 2013. DOI: 10.13140/2.1.4471.4881

Nicol, J. F., \& Humphreys M. A. (2009). New Standards for Comfort and Energy Use in Buildings. Building Research \& Information, 37(1), 68-73. https://doi.org/10.1080/09613210802611041

Nicol, J. F., \& Humphreys, M. A. (2010). Derivation of the Adaptive Equations for Thermal Comfort in Free-running Buildings in European standard EN15251. Building and Environment, 45, 11-17. https://doi.org/10.1016/j.buildenv.2008.12.013

Oliveira, A. M. (2016). Vãos Envidraçados, Desempenho Térmico e Conforto Térmico Humano, Modelo Simplificado de Seleção (PhD Thesis). Disponível em FEUP - Tese. (https://repositorio-aberto.up.pt/handle/10216/102588).

Poirazis, H. (2008). Single and Double Skin Glazed Office Buildings: Analyses of Energy Use and Indoor Climate (PhD Thesis). Lund University, Sweden. Available on:

https://vpp.sbuf.se/Public/Documents/ProjectDocuments/C015EF6E-22C6-4CA0-9B426A052F615F52/FinalReport/SBUF11247LicentiateThesis.pdf

Serra, V., Zanghirella, F., \& Perino, M. (2010). Experimental Evaluation of a Climate Façade: Energy Efficiency and Thermal Comfort Performance. Energy and Buildings, 42, 50-62. https://doi.org/10.1016/j.enbuild.2009.07.010

Singh, M.C., Garg, S.N., \& Jha, R. (2008). Different Glazing Systems and their Impact on Human Thermal Comfort - Indian Scenario. Building and Environment, 43, 1596-1602. https://doi.org/10.1016/j.buildenv.2007.10.004

Tzempelikos, A., Bessoudo, M., Athienitis, A., \& Zmeureanu, R. (2007). The Impact of Shading on Thermal Comfort Conditions in Perimeter Zones with Glass Facades. 2nd PALENC Conference and 28th AIVC Conference on Building Low Energy Cooling and Advanced Ventilation Technologies in the 21st Century, Crete Island, Greece, September, 2007.

Tzempelikos, A., Bessoudo, M., Athienitis, A., \& Zmeureanu, R. (2010). Indoor Thermal Environmental Conditions Near Glazed Façades with Shading Devices - Part II: Thermal Comfort Simulation and Impact of Glazing and Shading Properties. Building and environment, 45, $2517-1525$. https://doi.org/10.1016/j.buildenv.2010.05.014

Zhang, H. (2003). Human thermal sensation and comfort in transient and non-uniform thermal environments (PhD Thesis). University of California, Berkeley. Available on: https://escholarship.org/content/qt11m0n1wt/qt11m0n1wt.pdf.

Zhang, H., Yang, R., You, S., Zheng, W., Zheng, X., \& Ye, T. (2018). The CPMV index for evaluating indoor thermal comfort in buildings with solar radiation. Building and Environment, 134, 1-9. https://doi.org/10.1016/j.buildenv.2018.02.037 